\title{
Testing the Wear Mechanisms of the Components of Machines Used in Fossil Energy Resource Extraction
}

\author{
Andrzej N. Wieczorek ${ }^{1}{ }^{\mathbb{D}}$, Iwona Jonczy ${ }^{1, * \mathbb{D}}$, Patryk Bała ${ }^{2}$, Krzysztof Stankiewicz $^{3}{ }^{\mathbb{D}}$ and Marcin Staszuk ${ }^{4}$ \\ 1 Faculty of Mining, Safety Engineering and Industrial Automation, Silesian University of Technology, \\ Akademicka 2 Street, 44-100 Gliwice, Poland; andrzej.n.wieczorek@polsl.pl \\ 2 Rossmann, IT Department, Sw. Teresy Street, 91-222 Łódz, Poland; patrykbala89@gmail.com \\ 3 KOMAG Institute of Mining Technology, Division of Mechatronic Systems, Pszczyńska 37 Street, \\ 44-101 Gliwice, Poland; kstankiewicz@komag.eu \\ 4 Faculty of Mechanical Engineering, Silesian University of Technology, Konarskiego Street 18A, \\ 44-100 Gliwice, Poland; marcin.staszuk@polsl.pl \\ * Correspondence: iwona.jonczy@polsl.pl
}

check for updates

Citation: Wieczorek, A.N.; Jonczy, I.; Bała, P.; Stankiewicz, K.; Staszuk, M. Testing the Wear Mechanisms of the Components of Machines Used in Fossil Energy Resource Extraction. Energies 2021, 14, 2125. https:// doi.org/10.3390/en14082125

Academic Editor: Mehrdad Massoudi

Received: 9 March 2021

Accepted: 7 April 2021

Published: 10 April 2021

Publisher's Note: MDPI stays neutral with regard to jurisdictional claims in published maps and institutional affiliations.

Copyright: (c) 2021 by the authors. Licensee MDPI, Basel, Switzerland. This article is an open access article distributed under the terms and conditions of the Creative Commons Attribution (CC BY) license (https:// creativecommons.org/licenses/by/ $4.0 /)$.

\begin{abstract}
The paper presents the results of tests of wear of hardened wear-resistant steels in the presence of quartz, coal and coal-mineral abrasives of a differentiated ratios of each component and in the case without abrasives. The tests were carried out on a ring-on-ring test stand. Volume loss was the parameter used to characterize the wear level. Based on the Scanning Electron Microscopy (SEM) observations, different mechanisms of surface destruction depending on the type of abrasive were found. For the quartz abrasive, it was shown that the quartz grains cause micro-cutting, but surface cracks also appear that further transform into shallow holes. In the case of mixtures of quartz with coal, the surface was micro-scratched by quartz grains, but some of these grains were hammered into the surface, what was favoured by the presence of coal fractions. In the case of coal abrasive, traces of single cutting were observed, as well as unremoved scratches formed the sample grinding stage. Based on the wear observation, two models of steel surface wear in the presence of coal and coal-mineral abrasives were determined.
\end{abstract}

Keywords: wear; wear-resistant steels; abrasives

\section{Introduction}

Proper selection of construction materials aimed at minimizing the degradation processes of machinery and equipment surface layers requires understanding the wear mechanisms causing premature loss of durability [1,2]. The specific wear mechanisms, as well as the interactions between the wear processes during machine operation, are complex and depend on the components creating a given tribological system [3,4]. During the machines' operation, their components are exposed to intensified destruction of their surface, mainly during abrasive wear intensified by the impact of hard mineral abrasive grains, e.g., sandstones [5-9].

The adverse impact of hard mineral abrasives on the surface of machine components is well known and described in the published literature [10-15]. However, abrasive mixtures often are not homogeneous and may contain materials with significantly different wear properties [16]. Hard coal is an example of such type of material, often contaminated with a mineral substance, moreover, it may contain interlays of clastic rocks such as sandstone and mudstones as well as clay rocks. During longwall mining, the coal seam may be collected together with adjacent or subordinate rocks, e.g., in case of narrowing of the coal seam or in case of passing a fault. Also, during the roadway development with use of explosives or a roadheader, a mixture of rock crumbs and coal is formed. Its composition depends on the proportion of component minerals in the roadway cross-section. All the abovementioned factors make it impossible to consider hard coal a homogenous material just after mining, but rather as a mixture of minerals and coal [17]. 
Ngoy and Mulaba-Bafunbiandi [18] found a linear relationship between the abrasiveness of coal and the weighted hardness of the mineral components of such a coal. Petrica et al. [19] demonstrated a reduction in wear and frictional force of a hydrated mixture of coal and quartz sand in a pair of Hardox400-42CrMo-4 steel samples, compared to a mixture of only sand and water. They explained it as the effect of the lubricating properties of coal, but they did not explain the damage mechanisms or the role of coal in reduction of wear.

Xia et al. [20] tested the effect of water content, waste rock content, coal particle size, hard coal grinding index (HGI), normal load and speed of the conveyor chain, on the wear of wear-resistant steel of $490 \mathrm{HB}$ hardness. The results showed that wear increased with increase of water content, waste rock content, load and coal particle size, and at the same time decreased with increasing coal HGI and chain speed. On the basis of observations with the use of an optical microscope, they identified the following forms of steel damage as the dominant mechanisms: micro-scratching by hard particles, corrosion and fatigue surface chipping processes.

Tlotleng [21] tested the effect of such substances as coal, coal petrographic composition, grain composition, hard mineral content, HGI and water content on coal abrasiveness in the context of ensuring durability of coal crusher linings and grinding mills for liquid fuel production. The tests showed that water content and vitrinite content were the key factors increasing the abrasiveness of coal samples. The results also indicated that weathering the coal makes the coals less abrasive compared to unweathered coals. The author also pointed out that the increase in the content of grains of size below $75 \mu \mathrm{m}$ in the tested coal sample results in a reduction in wear, but the reason for this relationship was not explained.

Jonczy et al. [22] tested the wear for dry and hydrated hard coal with grain sizes smaller than $50 \mu \mathrm{m}$. Based on the tests, it was found that wear is caused by microcracking and fatigue-induced surface chipping. They also observed the coal being pressed into the surface roughness. After the end of wear tests, the abrasive tests showed that the hard coal contained in the abrasive may be transformed under the impact of local temperature and pressure increase. In the abrasive material transformed during the friction process, slight but measurable changes in carbon content in relation to the initial coal sample were found.

Wieczorek $[14,23]$ tested the wear of two wear-resistant steels and two structural steels in the presence of hard abrasives (corundum and quartz) and ground coal $(\mathrm{d}<50 \mu \mathrm{m})$ containing quartz and alumina. For hard abrasives, such as quartz, micro-scratching was found as the main reason of damage, while for coal it was fatigue-induced chipping. Despite the relatively high content of hard minerals in coal, the wear of wear-resistant steels in the presence of coal was approximately 20 times lower compared to corundum, and 10 times lower than quartz.

The majority of the abovementioned tests of abrasive properties of hard coal were conducted in the context of the operation of Armored Face Conveyors (AFC) components, such as the sliding metal sheets of troughs (AFC transporting hard coal is presented in Figure 1a, while a trough with scrapers and a chain is shown in Figure 1b).

During the run-of-mine transportation (transport of coal with interlayers), the scrapers move the coal lumps, which begin to break in a result of contact with other lumps or due to contact with steel surfaces. Fine fractions and pre-crushed coal and rock grains then get to the contact zone of the scraper and the trough, where they are further crushed. During the transportation process, between the scraper and the vertical chain link and the sliding steel plate there is a relatively homogeneous mixture of ground coal and mineral substances. Hard grains of rock raw materials or brittle grains of coal can continuously pass between the layer of the ground coal-mineral mixture lying on the trough and the scraper.

The impact of hard grains should be considered in the presence of coal dust. The mentioned work by Xia et al. [20] did not include its presence in their wear model. The change in destruction mechanism with presence of coal does not fully explain the low wear of steel, what was found by Wieczorek [14,23]. The surface may be worn by chipped fragments of the steel surface, what is a very intensive process. 


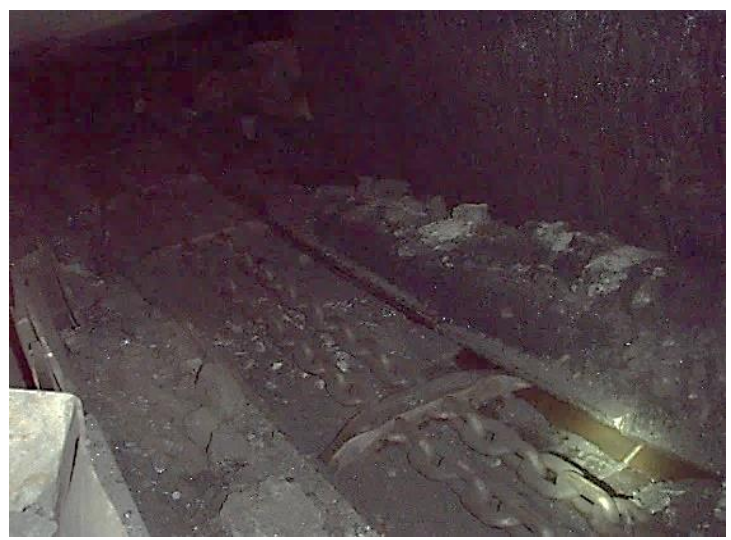

(a)

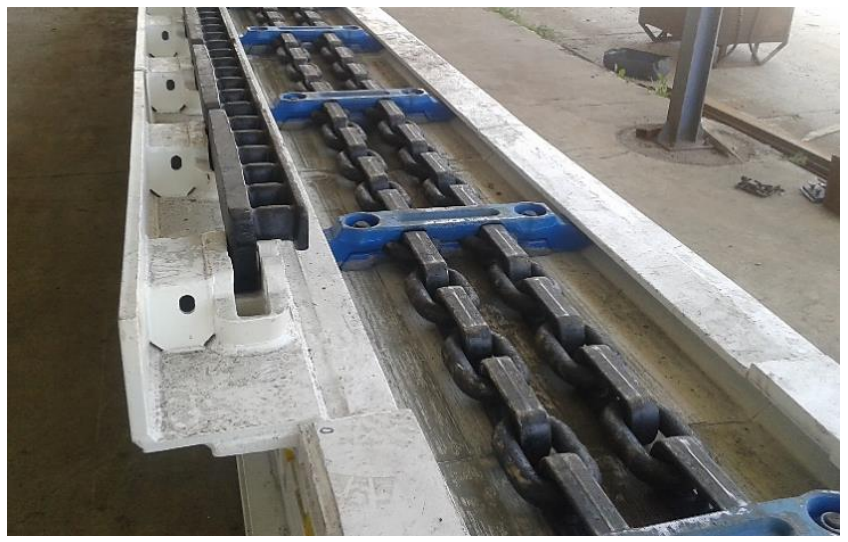

(b)

Figure 1. Armoured face conveyor; (a)—during the run-of-mine transportation, (b) —not loaded.

As part of the planned project, wear tests were carried out to recreate the real grinding process of quartz sand grains in the presence of fine coal grains (Figure 2). Moreover, the variants of wear with the presence of only coal particles and quartz grains were tested.

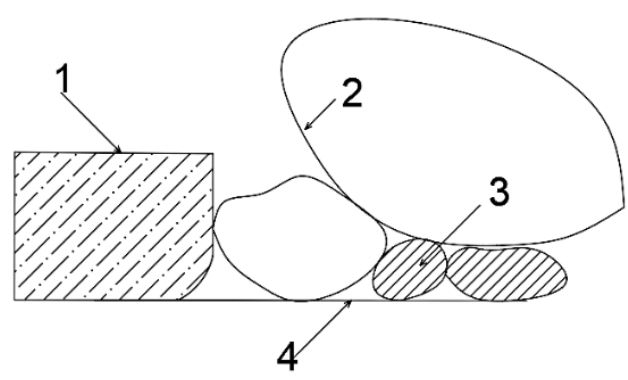

(a)

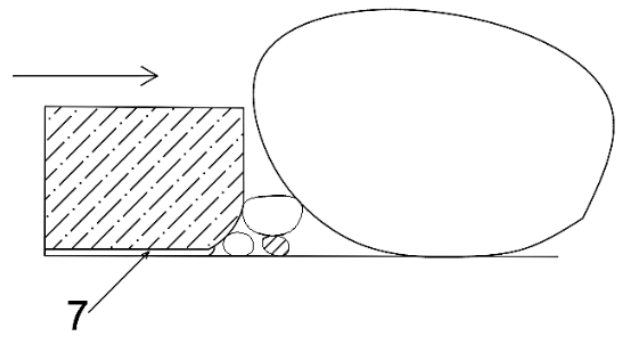

(c)

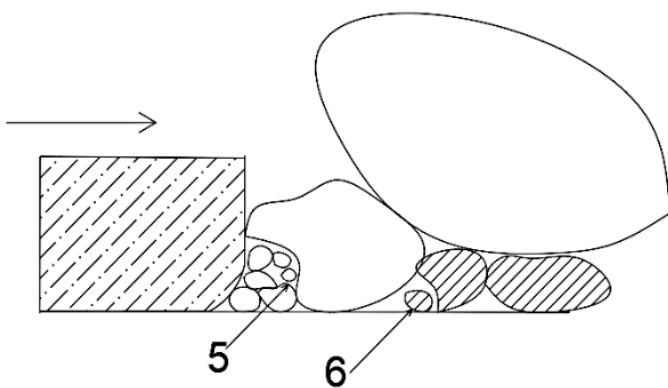

(b)

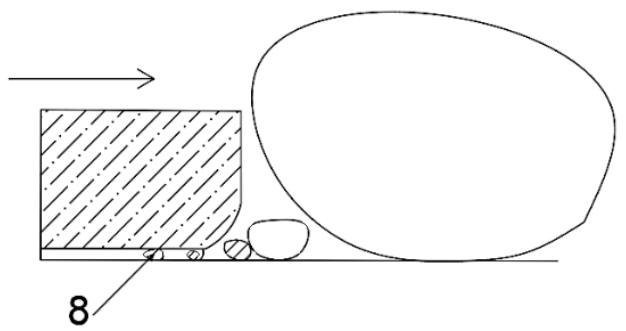

(d)

Figure 2. Model of the processes of coal grinding and sliding metal sheets wear, (a)-moving the blocks by a scraper, (b)—stage of initial crushing, (c)—stage of secondary crushing and creation of a ground coal layer, (d)—stage of wearing the trough surface by mineral grains and wear products in a presence of ground coal. 1—scraper, 2-coal grains, 3-rock grains, 4-sliding metal sheets of a trough, 5-ground coal grains, 6-ground rock grains, 7-layer of ground coal, 8-rock grains surrounded by ground coal.

The tests were mainly focused on clarifying the following issues:

- identifying the mechanisms of destruction of the surface of wear-resistant steels in the presence of coal-mineral mixtures

- quantitative impact of the quartz grain share in the coal-mineral mixture,

- interaction between ground coal and wear products or grains of hard abrasives. 


\section{Scope and Methodology of Testing}

Abrasive materials based on quartz sand, hard coal and their mixture were tested. Before starting the laboratory tests, the samples of abrasive were ground in the Retsch PM100 planetary ball mill.

The following tests were carried out:

- analysis of the chemical composition of the hard coal-based abrasive using the X-ray fluorescence method (XRF);

- determination of ash in the hard coal-based abrasive;

- wear tests (Section 3);

- microscopic observations of the surface of steel ring specimens after the wear tests with use of scanning electron microscopy.

Chemical composition of coal was analysed using the X-ray fluorescence method (XRF). The loss on ignition (LOI) at $815{ }^{\circ} \mathrm{C}$ was determined according to PN-EN ISO 12677: 2011. The sample, calcined to a constant mass, was fused with a mixture of lithium tetraborate, lithium metaborate and lithium bromide $(66.67 \%, 32.83 \%$ and $0.5 \%)$ of the flux purity for the XRF (Spex, Metuchen, NJ, USA). The weight ratio of the sample to the flux was 1:9.

The ash content was determined according to the PN-80/G-04512 standard at temperature of $815^{\circ} \mathrm{C}$, then the sample was calcined at temperature of $1025^{\circ} \mathrm{C}$.

Surface of the samples was observed using a scanning electron microscope (SEM) with the detection of secondary electrons (SE) at an accelerating voltage of $20 \mathrm{kV}$ and at a magnification within the range of 60-1000 $\times$. The qualitative analysis of the chemical composition in the micro-areas was performed by energy dispersive $X$-ray spectroscopy (EDS) at an accelerating voltage of $20 \mathrm{kV}$. The samples were sprayed with a thin layer of silver before testing to ensure discharging the static electricity. The $10 \mathrm{~nm}$ thick conductive layer was sputtered using a BAL-TEC SCD 050 sputtering machine (BalTec, Balzers, Germany).

\section{Experimental Details}

Impact of ground coal and its mixture with quartz sand on the wear of two martensitic wear-resistant steels with a nominal hardness of $400 \mathrm{HB}$, as well as the quartz sand itself, was analysed on a specially designed ring-on-ring test stand (Figure 3).

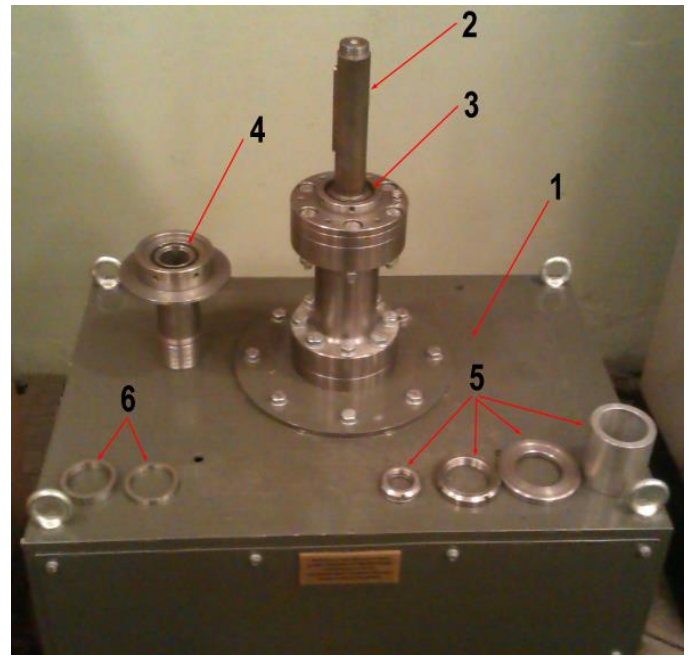

(a)

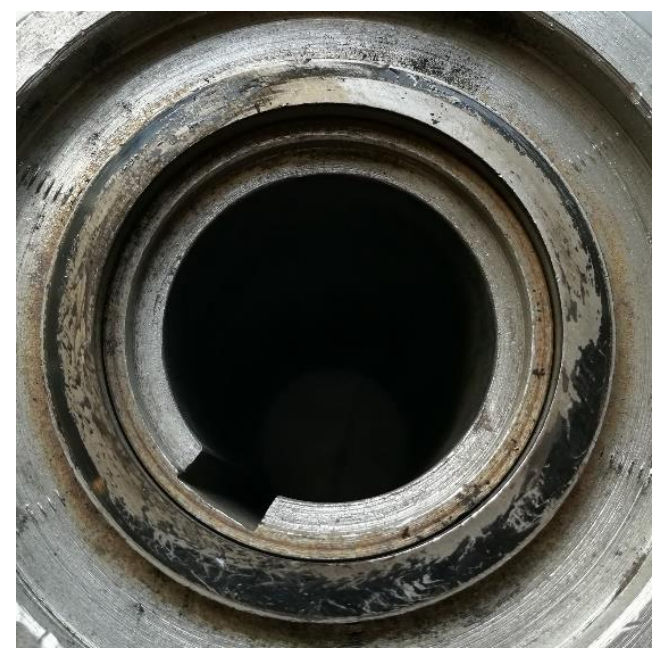

(b)

Figure 3. View of the test stand, (a) — components, (b) — testing head with the sample after the test with coal abrasive. 1-test stand body with a motor, 2-driving shaft, 3-upper sample handle, 4-bottom sample handle, 5-fixing components, 6-tested samples. 
The continuous presence, between the samples, of crushed abrasive grains and wear products formed from the damaged surface was a characteristic feature of the tests. This situation corresponds to the conditions of real wear of the scrapers and sliding metal sheets of AFC, during which hard rock fragments (e.g., sandstone) are crushed in the vicinity of a thin layer of highly fragmented hard coal.

As part of the wear tests, the impact of five types of abrasives (including three mixtures of coal with quartz sand) was considered for the tested steels, and only one steel was tested without abrasive between the samples surfaces, i.e., the surface wear was caused by cutting with the tops of the surface unevenness and with the resulting wear debris. The tested variants of the abrasives together with the tested steels and the type of run-of-mine transported by the conveyor assigned to them are given in Table 1.

Table 1. Tested variants of abrasives.

\begin{tabular}{|c|c|c|c|c|}
\hline Variant & Type of Abrasive & \multicolumn{2}{|c|}{ Tested Steels } & Stage of Work \\
\hline I & $100 \%$ Coal $(\mathrm{d}<50 \mu \mathrm{m})$ & WRS_400_I & WRS_400_II & Hard coal transport \\
\hline II & $25 \%$ Coal $(\mathrm{d}<50 \mu \mathrm{m})+75 \%$ Quartz $(\mathrm{d}<500 \mu \mathrm{m})$ & WRS_400_I & WRS_400_II & \\
\hline III & $50 \%$ Coal $(\mathrm{d}<50 \mu \mathrm{m})+50 \%$ Quartz $(\mathrm{d}<500 \mu \mathrm{m})$ & WRS_400_I & WRS_400_II & Transport of hard coal contaminated with \\
\hline IV & $75 \% \operatorname{Coal}(\mathrm{d}<50 \mu \mathrm{m})+25 \%$ Quartz $(\mathrm{d}<500 \mu \mathrm{m})$ & WRS_400_I & WRS_400_II & the waste rock \\
\hline $\mathrm{V}$ & $100 \%$ Quartz $(\mathrm{d}<500 \mu \mathrm{m})$ & WRS_400_I & WRS_400_II & Waste rock transport \\
\hline VI & Without abrasives (wear due to the surface unevenness) & WRS_400_I & - & Movement of scrapers off, no run-of-mine \\
\hline
\end{tabular}

The test for the selected variant of the abrasive consisted of eight 10 min cycles, after each cycle the samples were weighed and replenished with $1 \mathrm{~cm}^{3}$ of abrasive. Each test was repeated three times. The main parameters of the wear test are presented in Table 2.

Table 2. Main parameters of the wear tests.

\begin{tabular}{cc}
\hline Parameter & Amount \\
\hline Contact surface area S, $\mathrm{mm}^{2}$ & 785.3 \\
Pressing force F, N & 147.2 \\
Mass of the set load, $\mathrm{kg}$ & 15.0 \\
Compressing stress $\sigma, \mathrm{MPa}$ & 0.187 \\
Rotational speed of the moving sample, RPM & 149.1 \\
Average linear speed of the moving sample, $\mathrm{m} / \mathrm{s}$ & 0.29 \\
Tests duration, min & $8 \times 10$ \\
Sliding distance, $\mathrm{m}$ & 1390 \\
Number of test repetitions for each variant & 3 \\
\hline
\end{tabular}

Before the test, the samples were weighed on a laboratory balance with a resolution of $0.0001 \mathrm{~g}$. After each 10-min cycle of wear tests, the samples were thoroughly cleaned in a ultrasonic cleaner and reweighed.

During the tests weight loss of the sample $\mathrm{u}_{\mathrm{M}}$ was determined according to the following Equation (1):

$$
\mathrm{u}_{\mathrm{M}}=\left(\mathrm{m}_{\mathrm{pd} 0}-\mathrm{m}_{\mathrm{pdt}}\right)+\left(\mathrm{m}_{\mathrm{pg} 0}-\mathrm{m}_{\mathrm{pgt}}\right)
$$

where $\mathrm{u}_{\mathrm{M}}$-weight loss of the sample, $\mathrm{g} ; \mathrm{m}_{\mathrm{pd} 0}$ - mass of the bottom sample before the test, $\mathrm{g}$; $\mathrm{m}_{\mathrm{pdt}}$ - end mass of the bottom sample, $\mathrm{g}$; $\mathrm{m}_{\mathrm{pg} 0}$ - mass of the upper sample before the

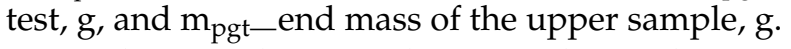

Volumetric loss was determined according to the following formula:

$$
u_{V}=\frac{u_{M}}{\rho}
$$


Based on the results also the Relative Wear Resistance (RWR) coefficient was also determined [24] according to the following formula:

$$
R W R=\frac{\text { Weight loss of sample }}{\text { Weight loss of sample of reference material (coal) }},
$$

The measurement uncertainty was determined using the Student's T-method for the confidence level equal to 0.95 and the number of tests $n=3$.

Martensite was the dominant phase of the both steels structure (sample microstructure of the WRS_400_I steel is shown in Figure 4a, in addition to it, there was a residual austenite in the amount of about $10 \%$.

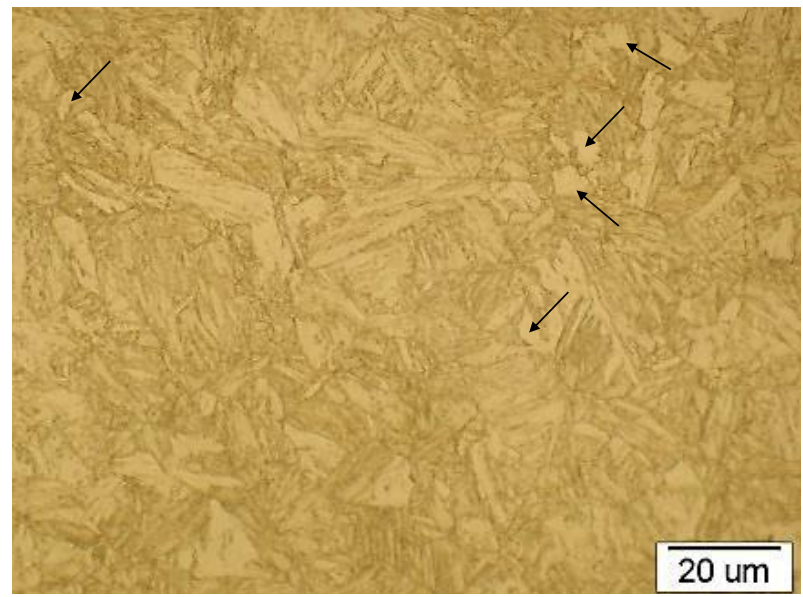

(a)

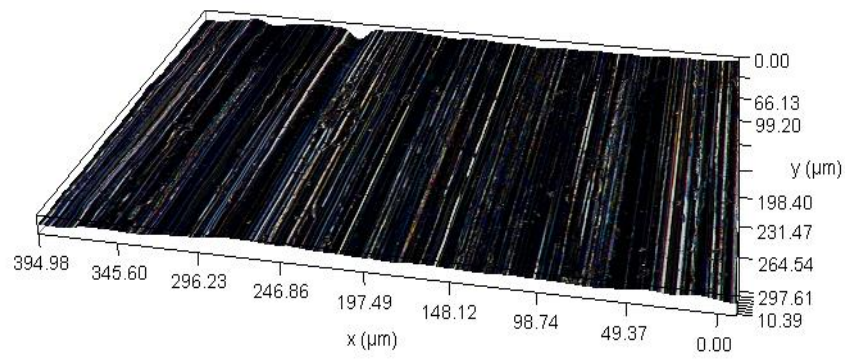

(c)

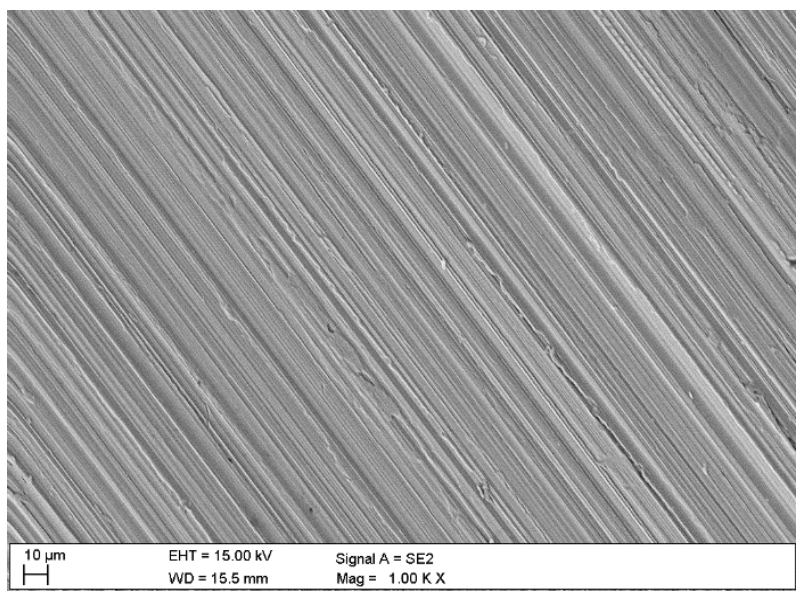

(b)

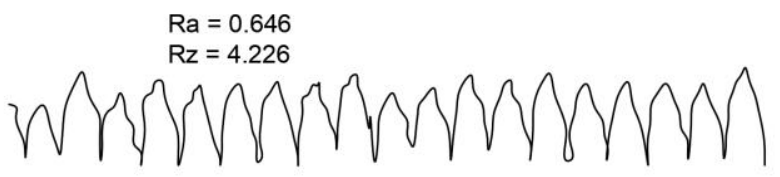

(d)

Figure 4. WRS_400_I steel, (a) Microstructure (OM), (b) surface view (SEM), (c) surface profile (DM), (d) roughness profile, areas of residual austenite are indicated by arrows.

Table 3 presents the maximum tensile strength TS, elongation and the measured surface hardness $\mathrm{HB}$ of the steel from which the samples for the wear tests were taken. The nominal hardness of the surface of both wear-resistant steels was $400 \mathrm{HB}$, however, the measured values was different (see Table 3). Hardness was measured using a FM-700 hardness tester (Future-Tech, Kawasaki, Japan).

Table 3. Mechanical properties of the tested steels.

\begin{tabular}{ccccc}
\hline Mechanical Properties & Tensile Strength TS, MPa & Elongation A, \% & $\begin{array}{c}\text { Minimum Temperature for Which the } \\
\text { Steel Impact Strength V is 30 J }\left({ }^{\circ} \mathbf{C}\right)\end{array}$ & Hardness, HB \\
\hline WRS_400_I & 1250 & 10 & -40 & 383 \\
WRS_400_II & 1300 & 12 & -20 & 403 \\
\hline
\end{tabular}

Table 4 gives the chemical composition of the tested wear-resistant steels. The chemical composition was determined using a SPECTROMAXx spectrometer from Spectro (Kleve, 
Germany). Steel samples were prepared by turning and grinding to form the rings with an internal diameter of $\varnothing 45$ and an external diameter of $\varnothing 55$, and a thickness of $6 \mathrm{~mm}$ (lower sample) and $10 \mathrm{~mm}$ (upper sample). The view of the surface after grinding obtained with the SEM microscope is shown in Figure 4b. The surface profile determined with a DVM6 digital microscope (Leica, Wetzlar, Germany) is shown in Figure 4c. The surface roughness was $\mathrm{Ra}=0.65 \mu \mathrm{m}$ (Figure $4 \mathrm{~d}$ ) for both materials (as determined using a MahrSurf 400 profilometer, Göttingen, Germany). During the tests, mineral abrasive was introduced between the rings.

Table 4. Chemical composition of the tested steels [mass \%].

\begin{tabular}{cccccccccc}
\hline \multicolumn{10}{c}{ WRS_400_I } \\
\hline $\mathrm{C}$ & $\mathrm{Mn}$ & $\mathrm{Si}$ & $\mathrm{S}$ & $\mathrm{P}$ & $\mathrm{Ni}$ & $\mathrm{Cr}$ & $\mathrm{Mo}$ & $\mathrm{B}$ & $\mathrm{Nb}$ \\
0.288 & 1.14 & 0.436 & 0.0124 & 0.0042 & 0.0782 & 0.457 & 0.122 & 0.0063 & $<0.0040$ \\
\hline \multicolumn{10}{c}{ WRS_400_II } \\
\hline $\mathrm{C}$ & $\mathrm{Mn}$ & $\mathrm{Si}$ & $\mathrm{S}$ & $\mathrm{P}$ & $\mathrm{Ni}$ & $\mathrm{Cr}$ & $\mathrm{Mo}$ & $\mathrm{B}$ & $\mathrm{Nb}$ \\
0.343 & 1.070 & 0.537 & 0.0144 & 0.0076 & 0.418 & 0.433 & 0.235 & 0.0041 & $<0.0040$ \\
\hline
\end{tabular}

The type of the abrasive used plays a key role in the developed test. As it was mentioned, pure quartz sand with a silica content of up to $90 \%$ was used in the test. Hard coal-based abrasive was the second type of used abrasive. Due to the fact that the coal collected for testing contained waste rock interlayers, its chemical composition was determined to check the amount of mineral substance in the coal [22] (Table 5).

Table 5. Chemical composition of the tested coal (maximum values in \%).

\begin{tabular}{cc}
\hline Component & Content (\% wag.) \\
\hline $\mathrm{L} . \mathrm{O} . \mathrm{I}$. & 74.11 \\
$\mathrm{SiO}_{2}$ & 14.82 \\
$\mathrm{Al}_{2} \mathrm{O}_{3}$ & 7.15 \\
$\mathrm{Fe}_{\text {total. }}$ calculated as $\mathrm{Fe}_{2} \mathrm{O}_{3}$ & 1.38 \\
$\mathrm{TiO}_{2}$ & 0.35 \\
$\mathrm{MnO}$ & 0.02 \\
$\mathrm{CaO}$ & 0.58 \\
$\mathrm{MgO}$ & 0.41 \\
$\mathrm{Na}_{2} \mathrm{O}$ & 0.14 \\
$\mathrm{~K}_{2} \mathrm{O}$ & 0.59 \\
$\mathrm{P}_{2} \mathrm{O}_{5}$ & 0.10 \\
$\mathrm{Cr}_{2} \mathrm{O}_{3}$ & 0.01 \\
$\Sigma$ & 99.66 \\
\hline
\end{tabular}

Based on the tests, it was found that the analysed coal abrasive contains quite significant amounts of minerals impurities, the chemical composition is dominated by $\mathrm{SiO}_{2}$ in the amount of $14.82 \%$. Apart from silica, the presence of $\mathrm{Al}_{2} \mathrm{O}_{3}(7.15 \%)$ and $\mathrm{Fe}_{2} \mathrm{O}_{3}(1.38 \%)$ is also noted, the content of other components did not exceed $1 \%$. The presence of silica is related to the quartz admixture, while the aluminium oxide and iron oxide content is related to the admixture of clay minerals.

Results of the chemical analysis also correlate with the determination of the ash content in the tested coal abrasive $(25.89 \%)$. Ash is a residue consisting of a mineral substance after the coal is completely burned at a given temperature. Based on the results, it can be concluded that the tested abrasive is made of high-ash coal. According to the literature data, the average ash content in hard coal ranges from $11 \%$ to $16 \%$ and depends mainly on sedimentation conditions and the type of organic matter $[8,9]$. 


\section{Results and Discussion}

One of the main objectives of the article was to determine, by microscopic observations of WRS_400_I steel, the mechanisms of surface destruction of wear-resistant steels in the presence of coal-mineral mixtures (the form of surface damage of both steels was identical, therefore the damage analysis was discussed on the example of only one steel grade).

Figures 5-9 show the surface the WRS_400_I steel after wear tests with the presence of coal (Variant I; see Table 6). Figure 5 shows partially coal-filled micro-cracks, most likely caused by wear debris, i.e., chipped particles of the steel surface. Some surface chippings are also visible as thin, relatively long cracks (Figure 5a). Coal is visible in the cracks, which may act as wedge on the crack formed during the fatigue processes. Different width of the crack along its length confirms that. Figure $5 \mathrm{~b}$ also shows grooves caused by surface grinding at the sample preparation stage. Similar traces of surface damage after wear in the presence of coal, as well as grinding traces, were presented by [20].

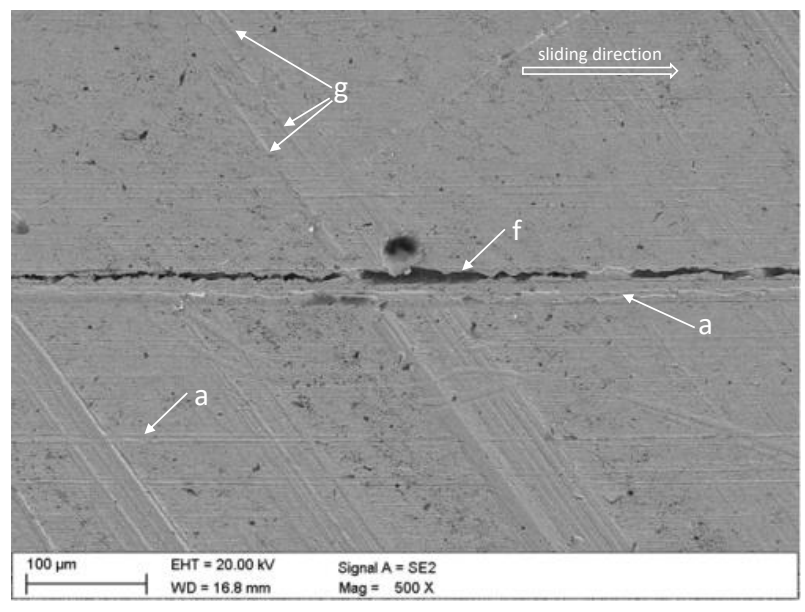

(a)

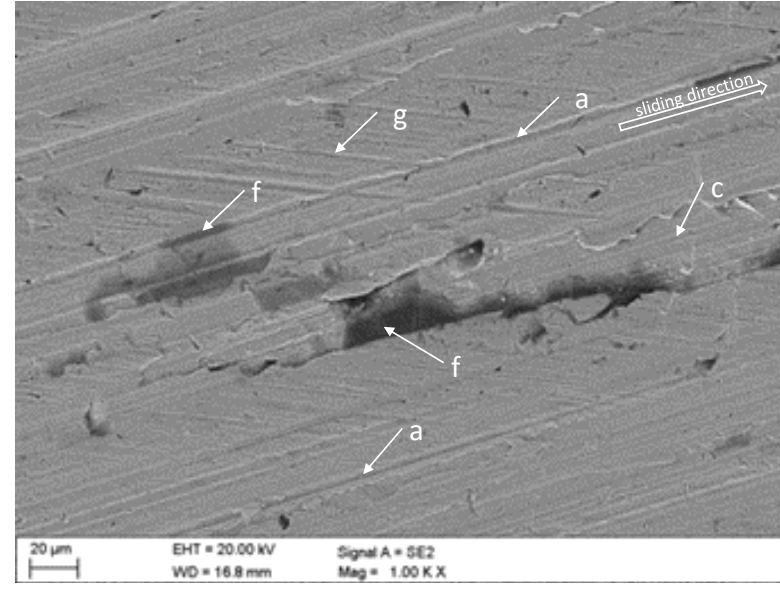

(b)

Figure 5. Surface views (SEM) of WRS_400_I steel after wear tests in the presence of coal, (a)—surface cracking against a background of grinding marks, (b) - micro-cracks partially filled with coal together with visible chipping; symbols: a-grooves, c-delamination, $\mathrm{f}$-coal-filled surface damage, g-sanding mark.

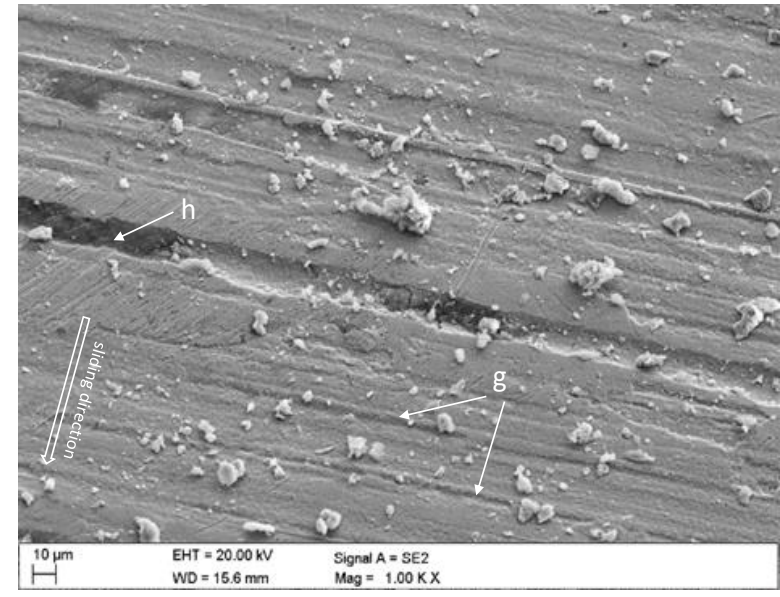

(a)

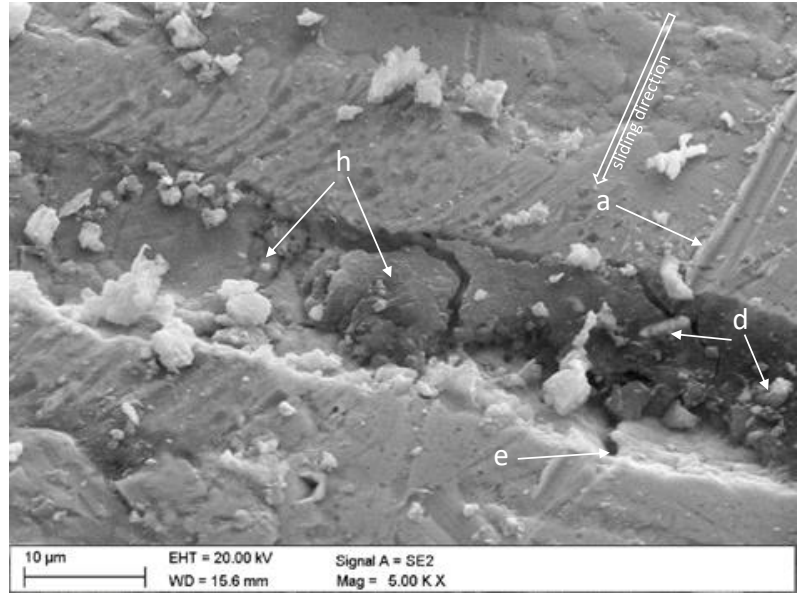

(b)

Figure 6. Sanding marks of WRS_400_I steel (a) filled with coal and crushed mineral grains (b) after testing in the presence of coal (SEM); symbols: a—grooves, d-debris, e-surface crack (exfoliation), g—sanding marks, h—coal-filled sanding marks. 


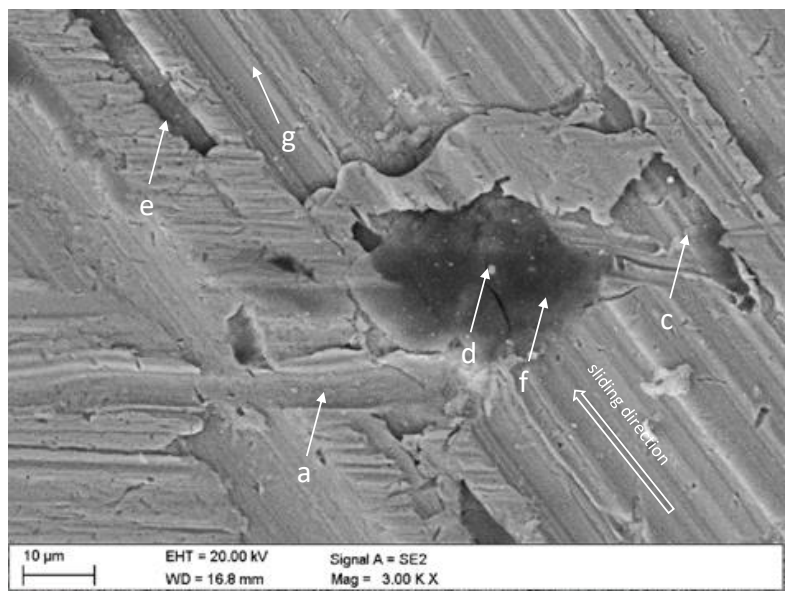

(a)

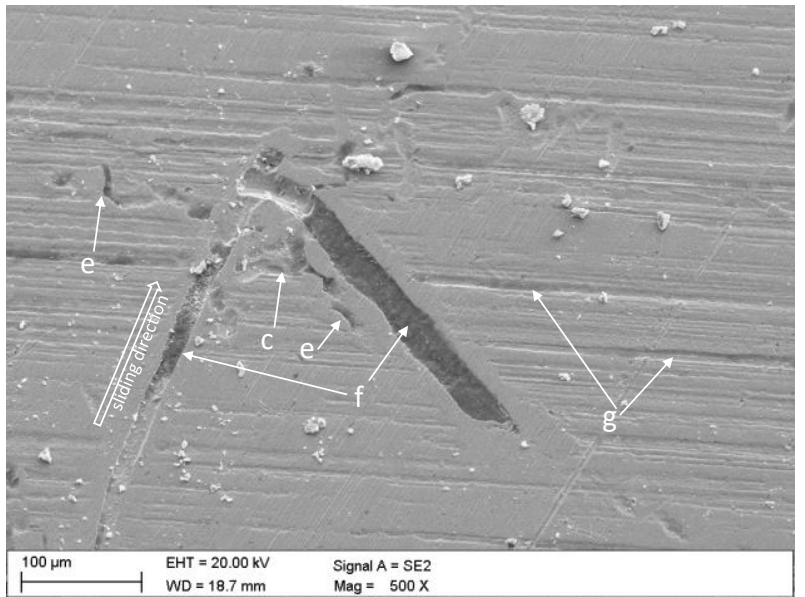

(b)

Figure 7. Examples of delamination of the surface of WRS_400_I steel in the area of contact between the sanding marks and the micro-cut caused by coal abrasive; symbols: a-grooves, c-delamination, $\mathrm{d}$-debris, e-surface crack (exfoliation), $\mathrm{f}$-coal-filled surface damage, $\mathrm{g}$ - sanding marks.

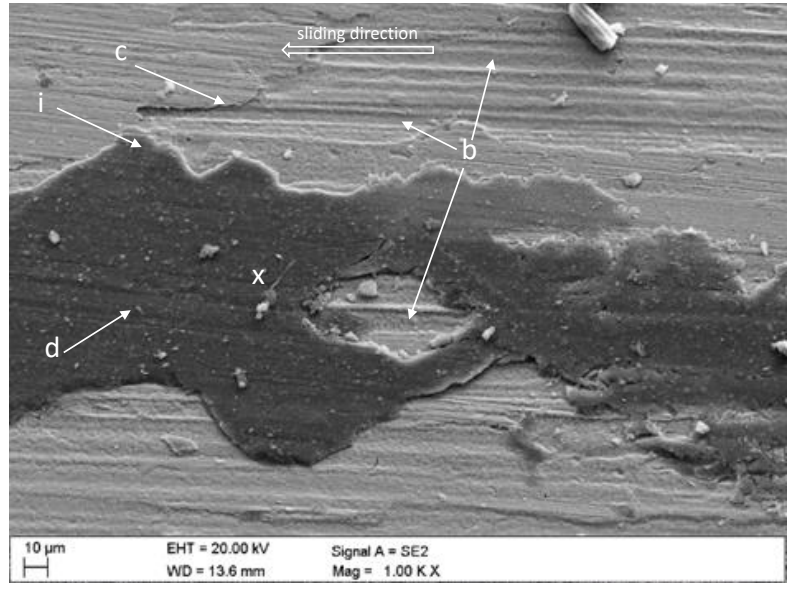

(a)

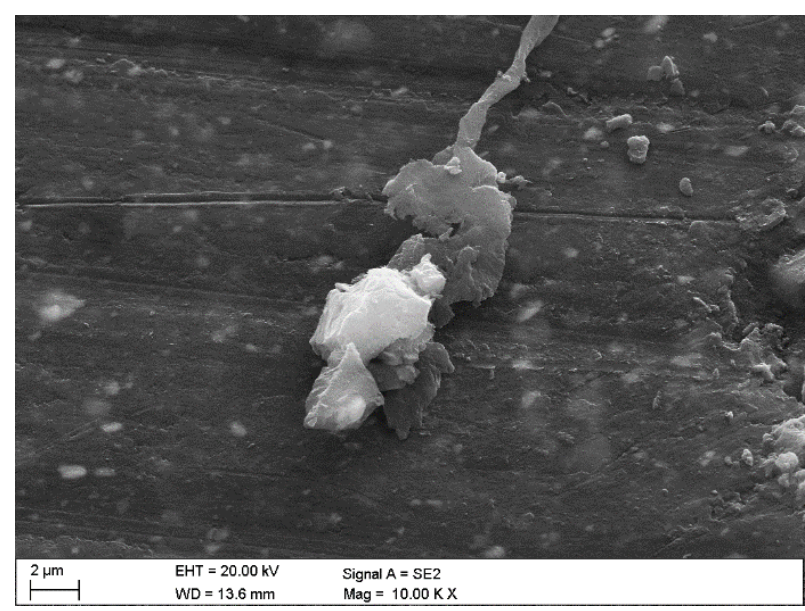

(b)

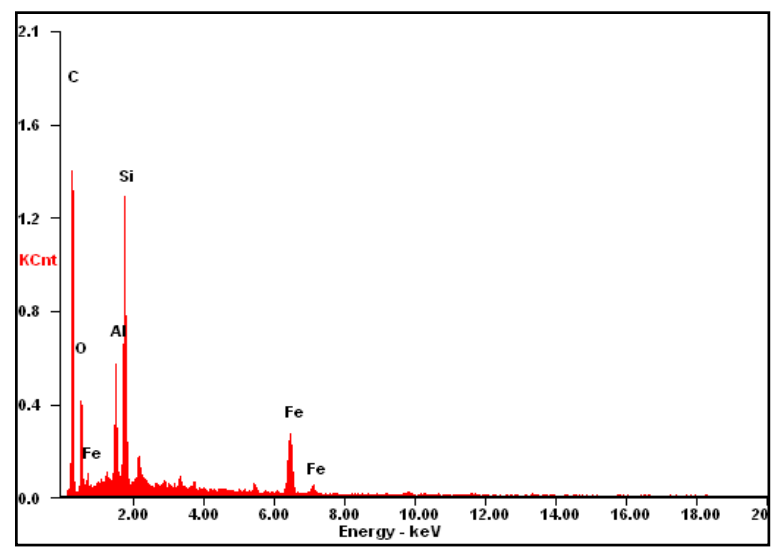

(c)

Figure 8. View of the coal layer pressed into the sample surface of WRS_400_I steel (a), the mixture of abrasive coal with crushed grains of minerals and wear debris (b) and EDS spectrum (c); symbols: b—plough, c—delamination, d-debris, $\mathrm{i}$-coal layer; $x$-EDS analysis point. 

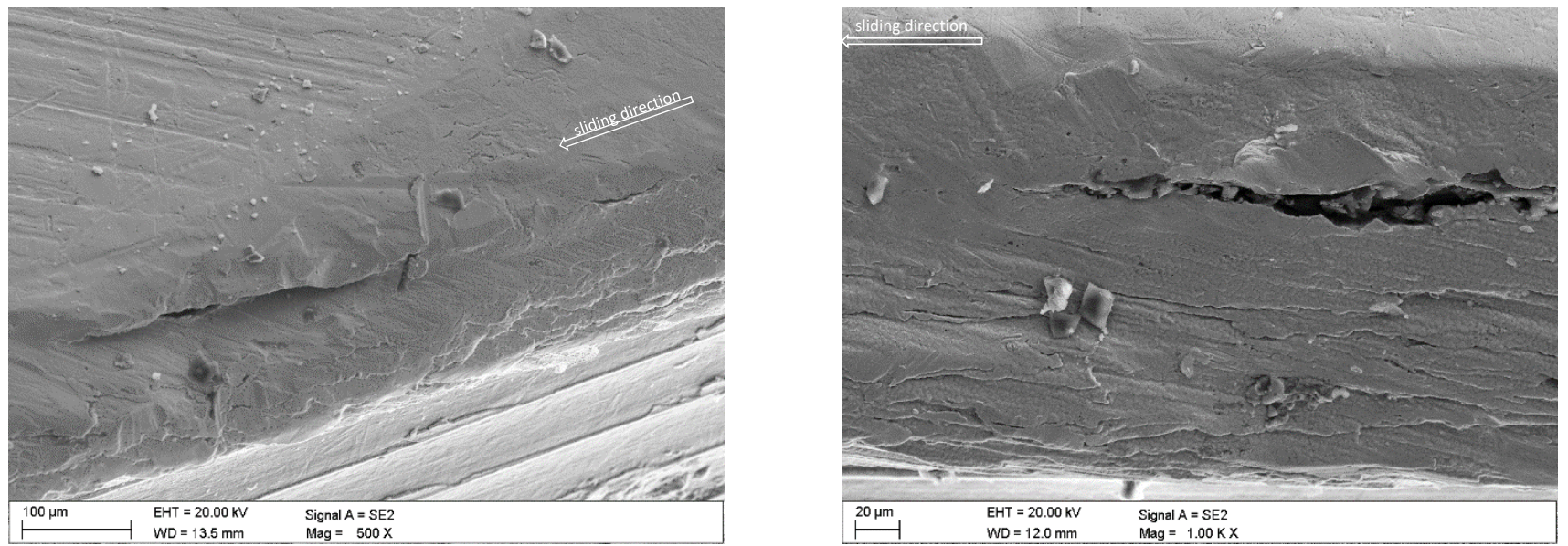

Figure 9. Views of the surface layer cracks in the area the side of roller of WRS_400_I steel's sample.

Table 6. Total mass wear $\mathrm{u}_{\mathrm{V} \Sigma}$ for the discussed materials.

\begin{tabular}{|c|c|c|c|}
\hline Variant No. & Type of Abrasive & $\mathrm{u}_{\mathrm{V \Sigma},}, \mathrm{mm}^{3}$ & RWR \\
\hline \multicolumn{4}{|c|}{ WRS_400_I } \\
\hline I & $100 \%$ Coal $(\mathrm{d}<50 \mu \mathrm{m})$ & 6.27 & 1.00 \\
\hline II & $25 \%$ Coal $(\mathrm{d}<50 \mu \mathrm{m})+75 \%$ Quartz $(\mathrm{d}<500 \mu \mathrm{m})$ & 49.77 & 7.94 \\
\hline III & $50 \%$ Coal $(\mathrm{d}<50 \mu \mathrm{m})+50 \%$ Quartz $(\mathrm{d}<500 \mu \mathrm{m})$ & 34.58 & 5.51 \\
\hline IV & $75 \%$ Coal $(\mathrm{d}<50 \mu \mathrm{m})+25 \%$ Quartz $(\mathrm{d}<500 \mu \mathrm{m})$ & 25.01 & 3.99 \\
\hline $\mathrm{V}$ & $100 \%$ Quartz $(\mathrm{d}<500 \mu \mathrm{m})$ & 61.03 & 9.73 \\
\hline VI & Without abrasives & 19.65 & 3.13 \\
\hline \multicolumn{4}{|c|}{ WRS_400_II } \\
\hline I & $100 \% \operatorname{Coal}(\mathrm{d}<50 \mu \mathrm{m})$ & 7.79 & 1.00 \\
\hline II & $25 \%$ Coal $(\mathrm{d}<50 \mu \mathrm{m})+75 \%$ Quartz $(\mathrm{d}<500 \mu \mathrm{m})$ & 50.06 & 6.42 \\
\hline III & $50 \%$ Coal $(\mathrm{d}<50 \mu \mathrm{m})+50 \%$ Quartz $(\mathrm{d}<500 \mu \mathrm{m})$ & 33.24 & 4.27 \\
\hline IV & $75 \%$ Coal $(\mathrm{d}<50 \mu \mathrm{m})+25 \%$ Quartz $(\mathrm{d}<500 \mu \mathrm{m})$ & 25.95 & 3.33 \\
\hline $\mathrm{V}$ & $100 \%$ Quartz $(\mathrm{d}<500 \mu \mathrm{m})$ & 61.21 & 7.86 \\
\hline
\end{tabular}

As shown in Figure 6a, coal can be pressed into the grooves in the result of pressure and friction, due to its plastic properties $[25,26]$. Figure $6 \mathrm{~b}$ shows a view of an approximately $3 \mu \mathrm{m}$ wide narrow groove caused by the action of a hard mineral grain, possibly quartz as a coal abrasive admixture. The size of such grain is smaller than the original size of the abrasive particles (approximately $50 \mu \mathrm{m}$ ), what proves their further crushing in the contact area of the cooperating samples. Particles of this size are visible in the area of the cut contact with the coal-filled groove after the grinding process. The coal that fills the grooves has the ability to absorb crushed hard mineral grains. In Figure $6 \mathrm{~b}$, a crack can be seen in the contact area of the cut with the after-grinding groove, which can initiate delamination, such as one shown in Figure 7. The contact areas of various types of cuts can thus induce extensive flat surface damage in the presence of variable load due to relative movement of the samples.

Coal from the abrasive also forms a layer (Figure 8a) adhering to the surface. This layer appeared after rough cleaning of the surface, the standard cleaning in an ultrasonic cleaner removes such layers from the samples and no artifacts are noticed. In Figure 8a, in addition to the coal layer, shallow delamination damages can be seen. Horizontal marks of widths not exceeding $5 \mu \mathrm{m}$, correlating with shallow indentations on the coal layer are visible on the sample surface, in the place not damaged by delamination, as well as in the delamination area.

The marks can result from plastic deformations caused by grains of hard mineral particles or wear debris (crushed steel particles), as also mentioned in Terva et al. [27] and Shao and Chen [28]. The coal layer, formed by the samples' interaction, is so strengthened 
that it can transfer compressive stresses into the surface layer, even to the material yielding point or fatigue cracks. This type of damage should be considered in the context of the delamination wear process $[29,30]$. Its essence is the assumption that in each sliding node, the contact point of the steel surface is subjected to cyclic loads transmitted by particles of abrasive. This results in an accumulation of both plastic deformation and stress in the nearsurface layer of the steel sample, resulting in the formation of cracks. As the contact area is loaded cyclically, the cracks may grow, initially they develop tangentially to the friction surface and then propagate inside the surface. As a final result of the fatigue process, a fragment of the subsurface layer will be separated in the form of a thin scale. Formation of wear debris, i.e., separated, fine steel particles which, due to their high hardness, can behave like a hard mineral abrasive, is frequently observed during cracking of the top layer. As a result of its impact on the surface of the tested steel samples, along with sand abrasive, symptoms of micro-cutting were observed.

Figure $8 \mathrm{~b}$ is an enlarged view of a surface-pressed coal layer with visible fine abrasive particles or a crushed surface of steel samples mixed with the layer material. EDS analysis confirms the presence of hard grains composed of $\mathrm{SiO}_{2}, \mathrm{Al}_{2} \mathrm{O}_{3}$ and iron oxides in the coal coating (Figure 8c). The ability of transmission of load by the layer of pressed and consolidated coal, which initiates steel plasticization and delamination is confirmed by the surface view in Figure 9. This figure shows surface layer cracks arranged parallel to the surface, at various stages of damage development. The cracks were found near the outer cylinder of the sample and were located at a depth of about $100 \mu \mathrm{m}$.

Steel surface after wear tests in the presence of coal (Variant I) significantly differs in the degree of damage compared to the surface after the tests with abrasives containing the hard grains of quartz. A view of the WRS_400_I steel surface after wear tests in the presence of a mixture of $25 \%$ coal and $75 \%$ quartz sand is shown in Figure 10 . Numerous micro-cuts, a significant part of which is filled with hard coal are characteristic for the damaged surface (Figure 10a).

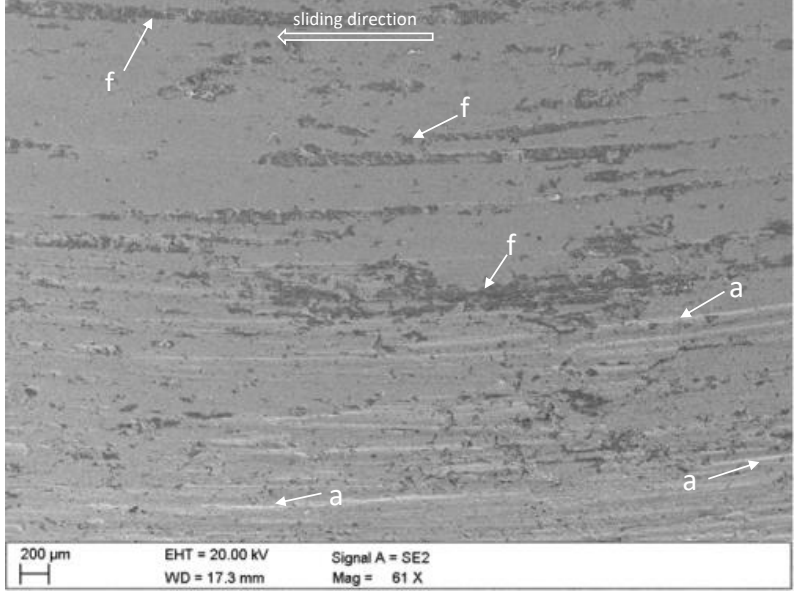

(a)

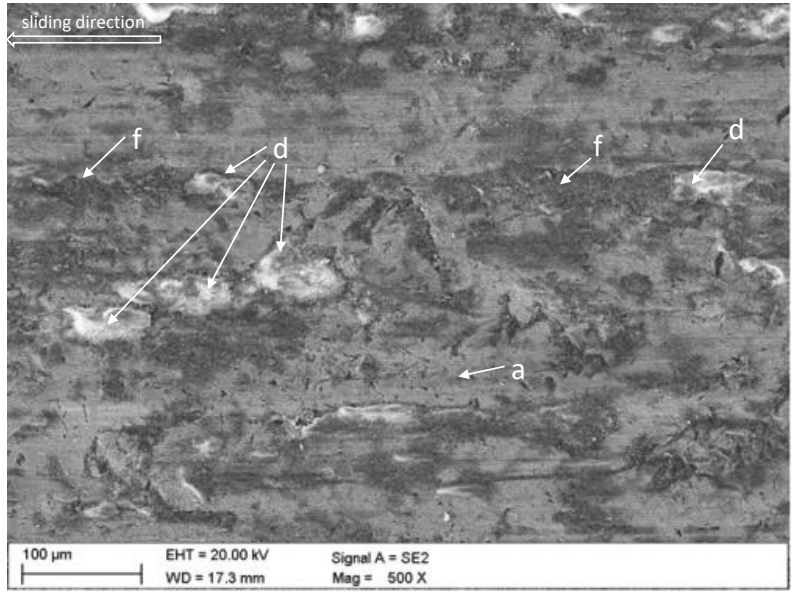

(b)

Figure 10. Views of WRS_400 steel surface (SEM) after tests with a mixture of $25 \%$ coal and $75 \%$ quartz sand (Variant II), cuttings filled with a coal-quartz mixture (a), crushed quartz grains in cavities filled with hard coal (b); symbols: a-grooves, $\mathrm{d}$-debris, $\mathrm{f}$-coal-filled surface damage.

The crushed quartz grains are clearly visible in the areas filled with coal (Figure 10b). These grains have smoothed surfaces, what suggests that they were placed on the samples surface for a long time and had an impact on the cooperating counter-sample surface. This proves that the form of "two-body abrasive wear" can occur simultaneously with the form of "three-body abrasive wear" [24,31]. Damage in the form of fatigue chipping cannot be ruled out for the analyzed abrasive variant, as its possible traces were covered with the 
pressed hard coal. In the central part of Figure 10a there is a fairly large area filled with coal, which may have influenced the result of fatigue mechanisms.

Forms of damage found for WRS_400_I and WRS_400_II steels after wear tests with a mixture of $50 \%$ coal and $50 \%$ quartz sand (Variant III) were identical to those for the mixture of $25 \%$ coal and $75 \%$ quartz sand (Variant II).

In the case of the mixture of $75 \%$ coal and $25 \%$ quartz sand (Variant IV), the basic mechanisms of wear in the form of micro-cutting and surface chipping (delamination) were found (Figure 11a), similarly to other coal-quartz mixtures, also the number of cavities filled with a coal abrasive was reduced. Crushed grains of the hard abrasive may also be located in these few cavities filled with coal (Figure 11b). For the discussed case, a reduction in the cutting action of quartz grains on the surface is noticeable, as the coal layer that is probably formed at the same time partially protects this surface against deeper cutting. However, this layer does not exclude the possibility of fatigue chippings laying in parallel to the surface.

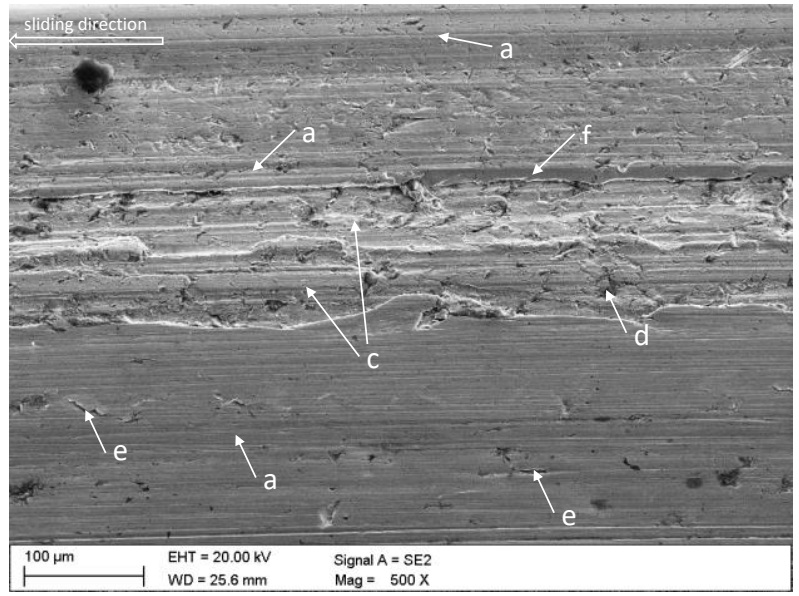

(a)

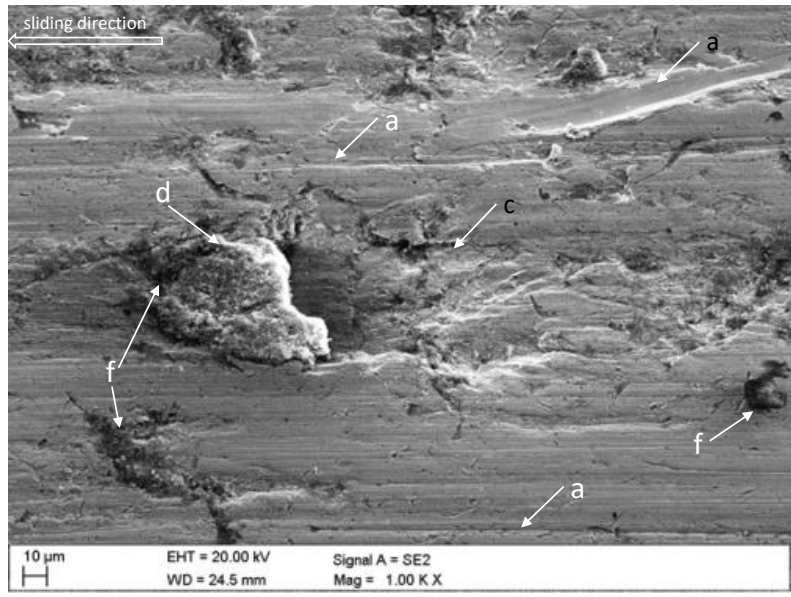

(b)

Figure 11. Views of WRS_400 steel surface (SEM) after the tests with a mixture of $75 \%$ coal and $25 \%$ quartz sand (Variant IV), view of the fatigue chipping (a,b); symbols: a-grooves, c-delamination, $\mathrm{d}$-debris, e-surface crack (exfoliation), $\mathrm{f}$-coal-filled surface damage.

Figure 12 shows sample views of the surface damage of WRS_400_I steel after wear tests with the presence of quartz sand (Variant $V$ ). As a result of the grains interaction, the surface of the tested samples had a damage mainly in the form of numerous micro-cuts (Figure 12a). Single grooves were also found. Smoothed or partially obliterated cut areas between deeper cuts, as well as the surfaces with numerous surface cracks were observed (Figure 12b). These cracks later turned into flat chipping. The flat chipping could also arise from brittle horizontal cracks formed during cutting. The side edges of the cracks are uneven, stepped, partially detached steel particles are found at the bottom of the cracks (Figure 12c), what was confirmed by EDS analysis (Figure 12d).

Testing the wear-resistant steels without using abrasives was the last variant (Variant VI). In this variant the cooperating surfaces touched each other through the peaks of roughness (Figure 13). Formation of numerous cuts filled with corrosion debris was the effect of the surfaces' cooperation. These cuts were not only caused by the protruding tops, but were also a result of the cutting action of the steel particles detached in a result of direct contact (a view after detachment of such a particle is shown in Figure 13b). The areas between the cuts had a smoothed surface, and the observed corrosion debris were found below the slip area of the samples. This proves that corrosion was formed immediately after the cutting and that oxygen had access to the exposed surface during the wear process. The surfaces exposed in a result of the impact of hard steel particles were highly susceptible to oxidation. 


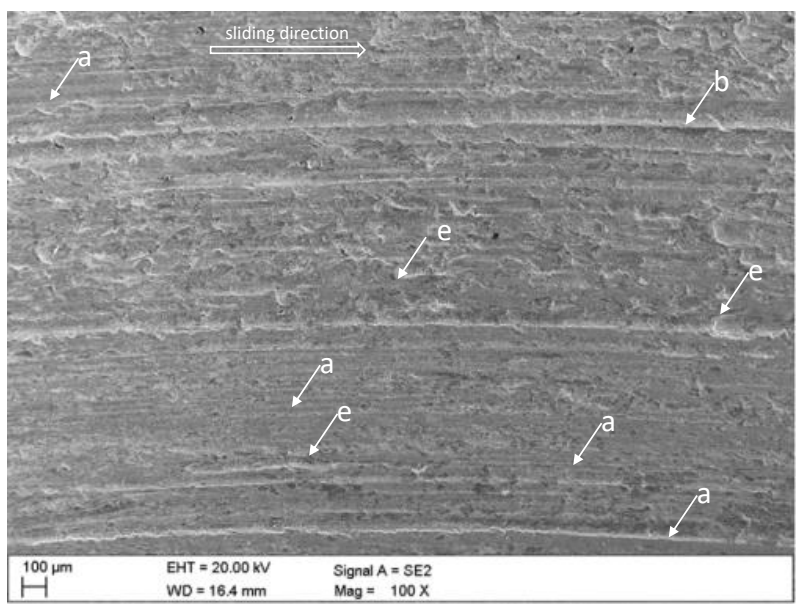

(a)

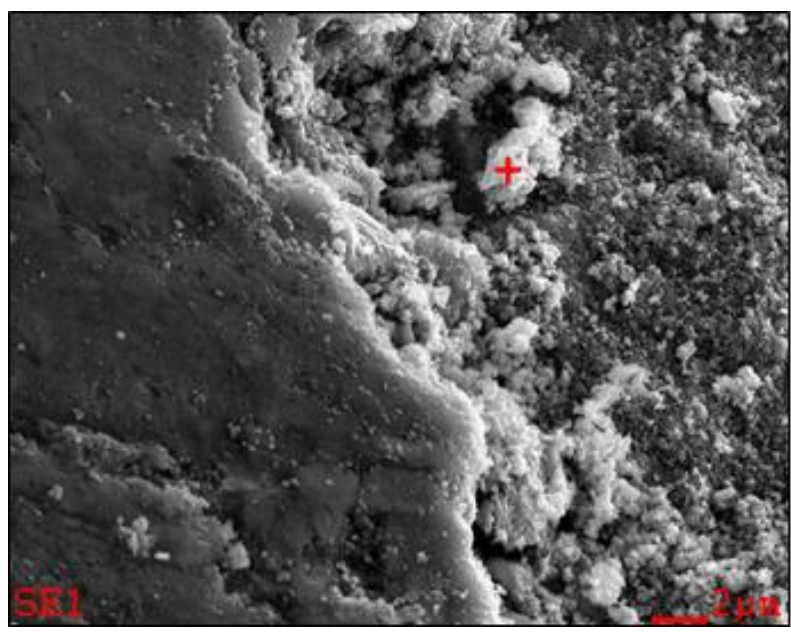

(c)

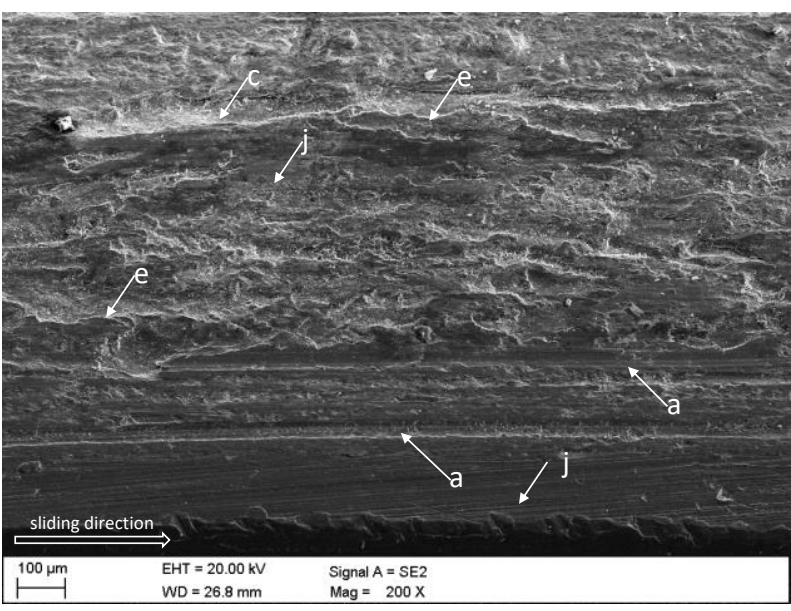

(b)

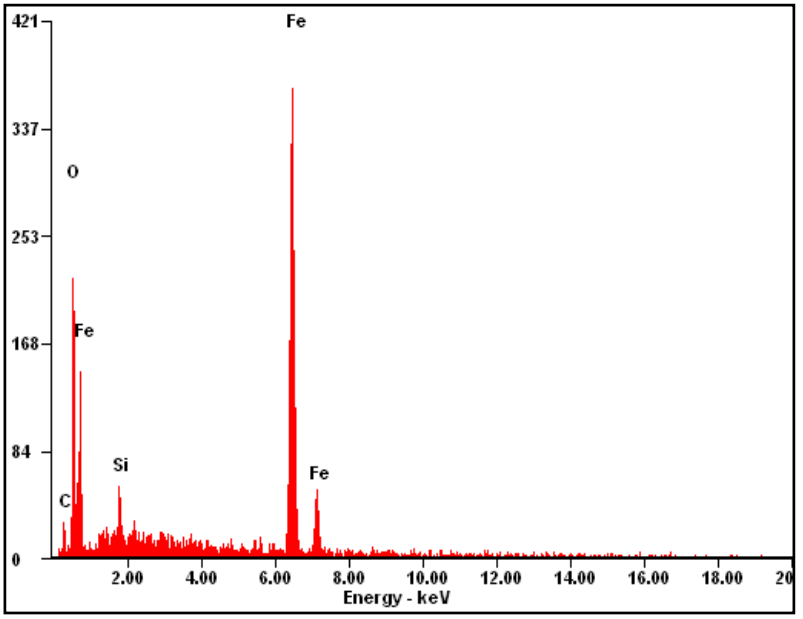

(d)

Figure 12. WRS_400_I steel after the tests with the quartz abrasive (Variant II), views of damages in a form of chippings caused by quartz abrasive-SEM (a,b); view of the steel fragments in the area of surface chipping (c), result of EDS analysis (d); symbols: a-grooves, b-plough, c-delamination, e-surface crack (exfoliation), j-smoothing the surface.

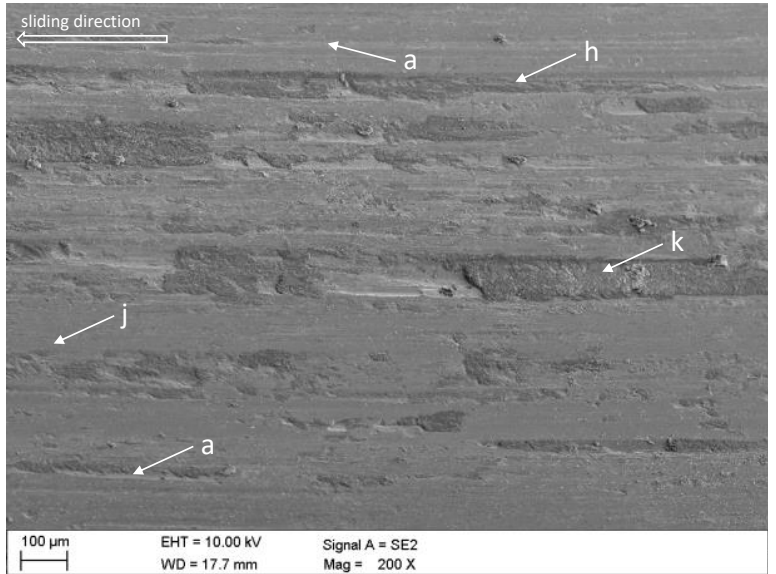

(a)

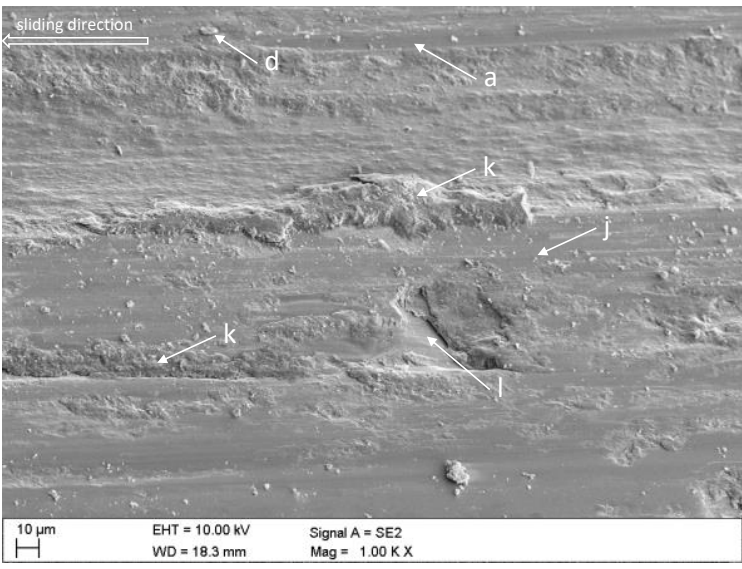

(b)

Figure 13. Views of WRS_400_I steel $(a, b)$ after the tests without using the abrasive (Variant VI), SEM; symbols: a一grooves, $\mathrm{h}$-coal-filled sanding marks, $\mathrm{j}$-smoothing the surface, $\mathrm{k}$-corrosion products, 1 -gap. 
Corrosion products of this type were only observed for the variant of wear without abrasives. The lack of corrosion traces for the wear variant in the presence of quartz is due to the high intensity of the micro-cutting process by the crushed and non-crushed grains, which led to the removal of possible oxidation products. In the case of coal wear variants (with and without quartz sand), the surfaces exposed to cutting were covered with a layer of consolidated coal, which could reduce the intensity of the oxidation process, and even completely eliminate it.

Quantification of the effect of quartz grain content on the wear of wear-resistant steels was the second main objective of the project. Figures 14 and 15 show the volumetric wear curves for the considered abrasive variants in a function of the test duration for both steels, while Table 6 summarizes the determined total volumetric wear $u_{V}$ and RWR index determined on its basis.

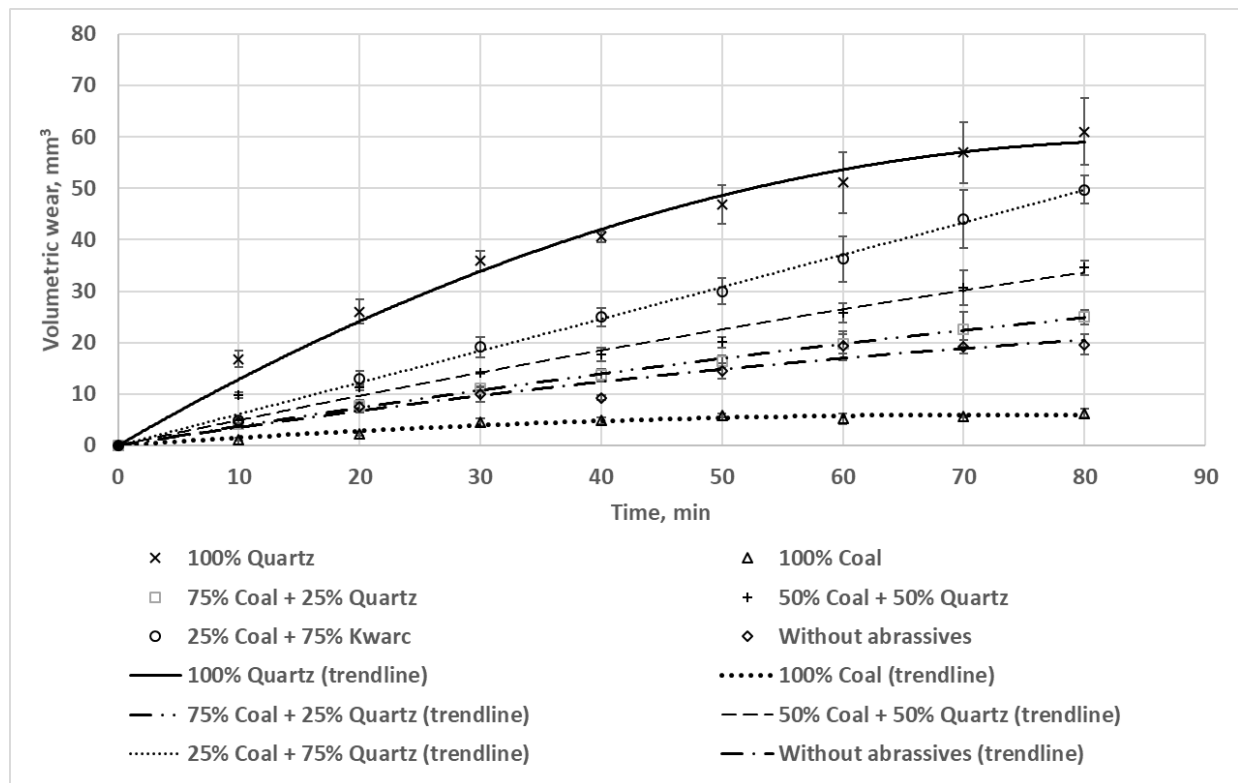

Figure 14. Time processes of volumetric wear $\mathrm{u}_{\mathrm{V}}$ of WRS_400_I steel for the discussed wear variants.

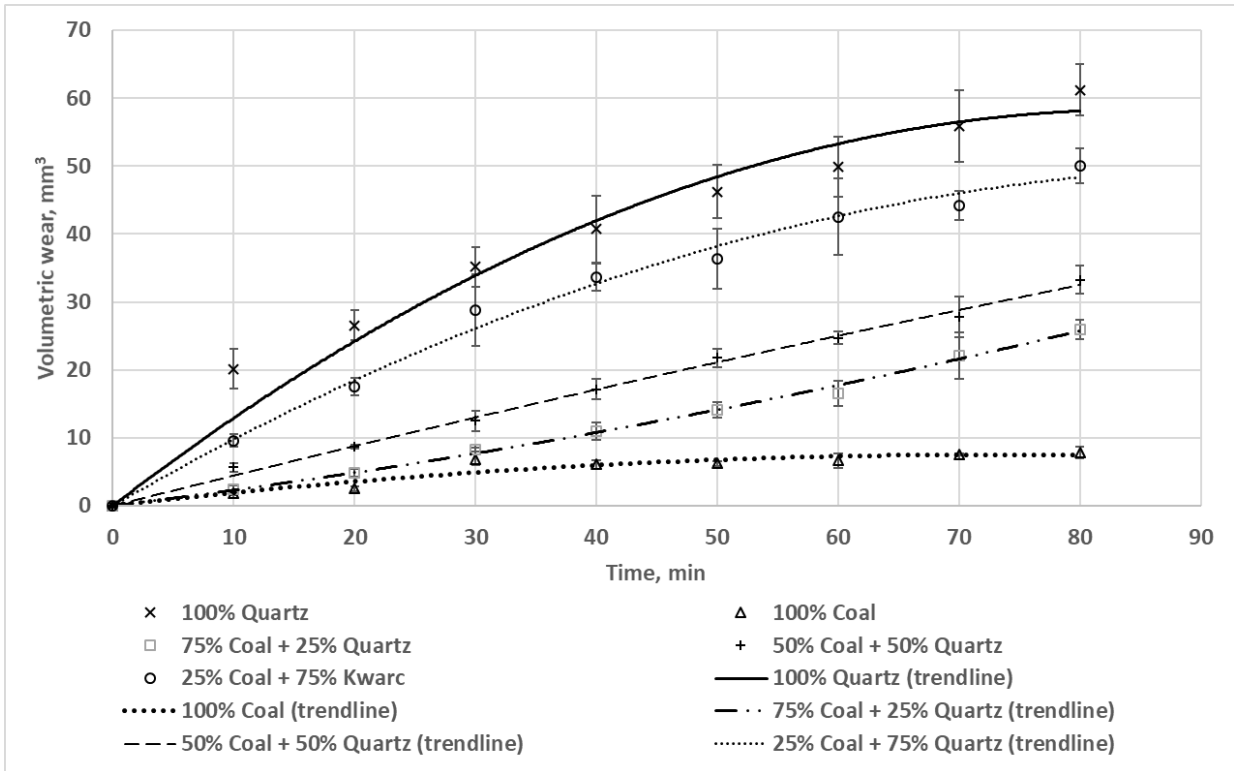

Figure 15. Time processes of volumetric wear $\mathrm{u}_{\mathrm{V}}$ of WRS_400_II steel for the discussed wear variants. 
When comparing the obtained results, the following conclusions were drawn for both considered wear-resistant steels:

- the highest wear was observed for homogeneous hard mineral abrasives (quartz sand),

- the wear of both wear-resistant steels are very close to each other,

- in the case of coal-quartz mixtures, the wear decreased linearly with a decrease in the share of hard grains (Figure 16),

- wear in the presence of coal abrasive was lower than wear without the abrasive, i.e., when abrasive wear was caused by the peaks of the surface roughness,

- the lowest wear was observed for coal abrasive and it was almost 10 times lower compared to the wear found for the variant of the abrasive containing quartz.

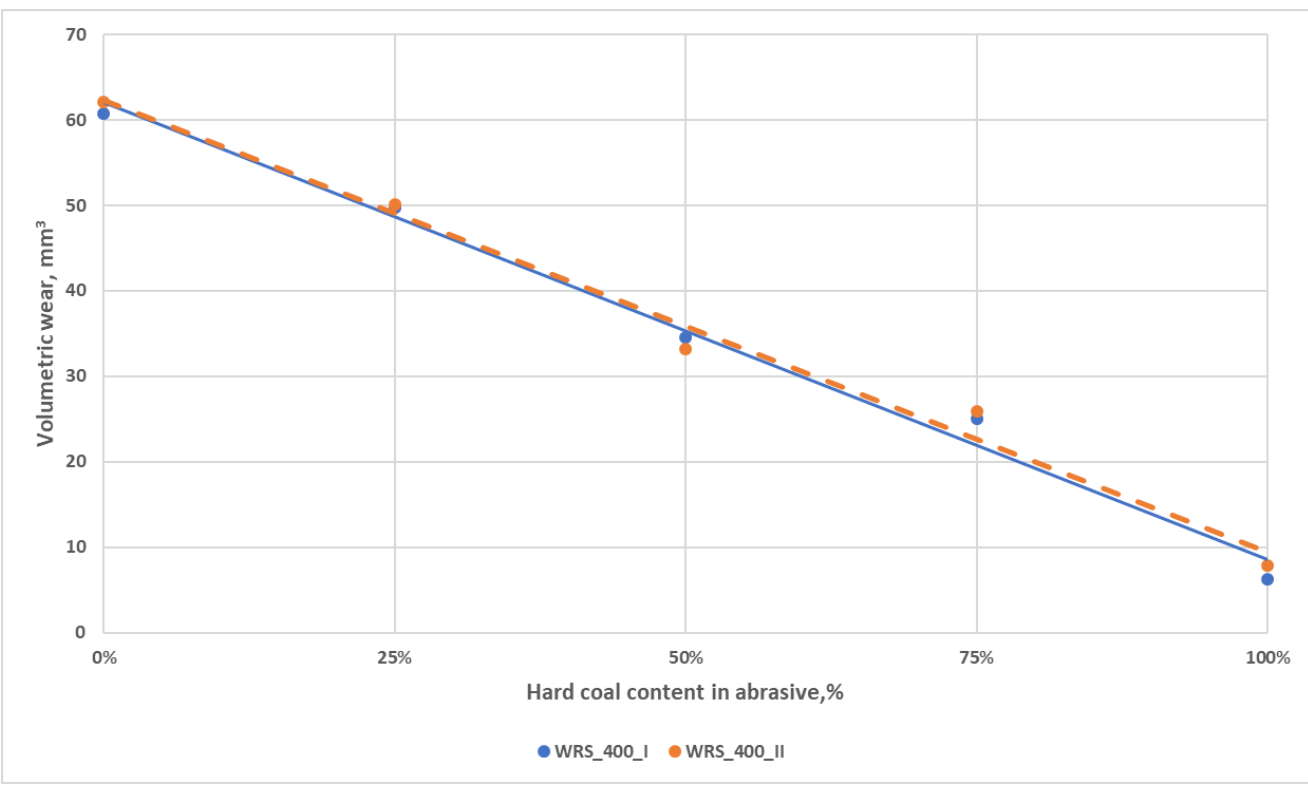

Figure 16. Final volumetric wear $\mathrm{u}_{\mathrm{V}}$ of WRS_400_I and WRS_400_II steels in a function of coal content in a coal-quartz abrasive; the diagram includes the result for quartz abrasive $(0 \%$ of hard coal) and coal abrasive (100\% of hard coal).

The differences found in the wear of wear-resistant steel surfaces can only partially be explained by a type of surface destruction dominating for each abrasive variant: tribological wear (in particular, abrasive wear) or low-cycle fatigue, accompanied by corrosion. Low wear intensity in the presence of crushed coal, containing however, a significant amount of hard minerals $\left(\mathrm{SiO}_{2}\right.$ and $\left.\mathrm{Al}_{2} \mathrm{O}_{3}\right)$ is especially interesting. Possible interactions between the coal abrasive, indicating the ability to fill voids after cutting or delamination, forming consolidated layers, and the wear debris, can be the answer.

In the case when only crushed grains of coal get between the cooperating surfaces, the coal abrasive under the load and friction can consolidate into a fairly plastic layer that will also cover and fill in the surface irregularities which appeared during manufacture of wear-resistant steels. The consolidated coal layer is most likely free from internal pores, and therefore cyclical loads can be transferred from one surface to another, resulting in the initiation of fatigue cracks and the formation of flat surface chippings. The propagation of fatigue cracks can be accelerated by pressing the compressed coal into them (coal wedge), and also intensified in the contact zones of surface irregularities caused by steel manufacture and cuts resulting from wear. The detached steel particles may be further crushed, while some of them cut the surface of cooperating parts, and some of them press into the coal layer becoming inactive. Surface oxidation at the point of delamination can be limited by a consolidated coal layer as well as by close contact of irregularities of the cooperating surfaces. 
Based on the analysis and the presented concept of formation of a consolidated coal layer, a wear model of the real tribological system i.e., a scraper sliding on the surface of a metal sheet with the presence of coal (Figure 17), was developed. This model does not apply to a single cycle of the scraper sliding on the metal sheet surface, but to the situation of multiple repetitions, until the effects of low-cycle surface chipping occur.

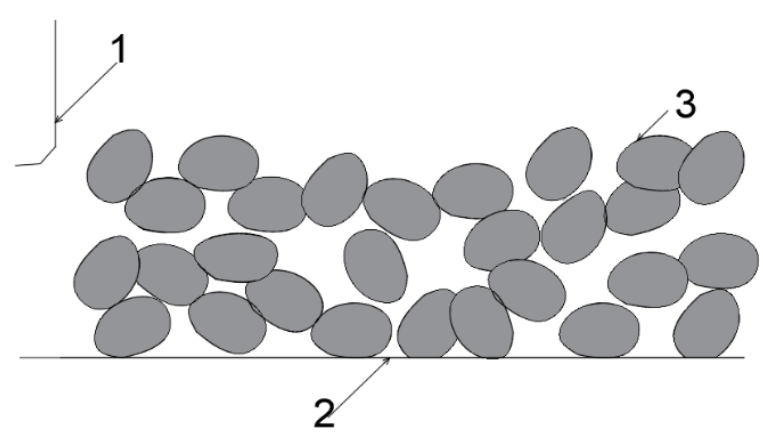

(a)

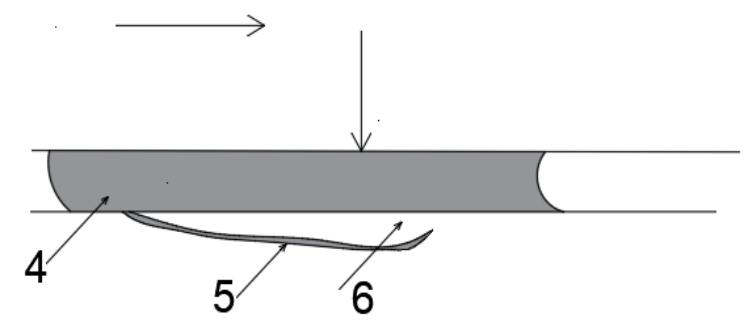

(c)

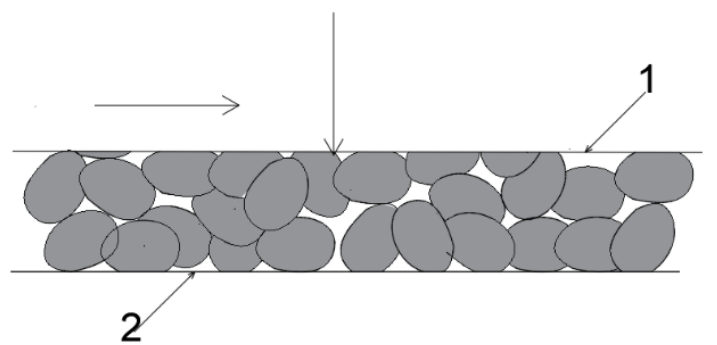

(b)

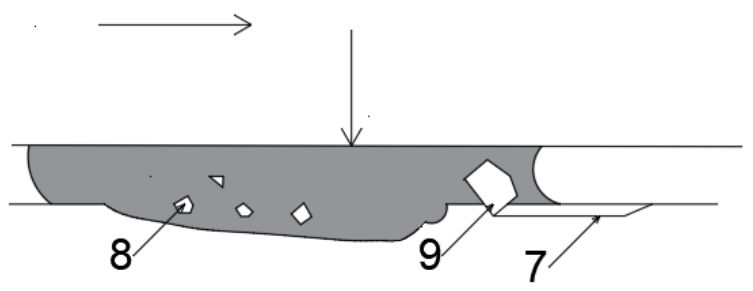

(d)

Figure 17. Wear model of the real system with the presence of coal grains: scraper sliding on the metal sheet surface, (a)-Stage I (initial state), (b)—Stage II (crushing and initial consolidation of coal grains under the load and the scraper advance), (c) - Stage III (complete crushing, final consolidation of the surface layer and fatigue chipping), (d) - Stage IV (crushing of chipping debris and surface cutting by the wear debris); symbols: 1-scraper, 2 -metal sheet, 3-coal grains, 4-consolidated coal layer, 5-coal wedge, 6-flat fatigue fracture, 7-micro-cut, 8—crushed debris particles located in the coal layer, 9 -incompletely crushed debris particle.

The presented model of wear of the real system: a scraper sliding on the metal sheet surface in the presence of only coal grains includes the following four stages:

- Stage I: fine grain fractions of transported coal move to the metal sheet surface before contact with the scraper,

- Stage II: crushing and initial consolidation of coal grains under the load and the scraper advance,

- Stage III: final consolidation of the coal layer combined with grain crushing of the coal fractions and initiation of fatigue crushing of the surface,

- Stage IV: crushing of wear debris and cutting the surface by larger steel fragments and partial inactivation of smaller particles by the consolidated fraction of fine coal grains.

In the case of coal-mineral abrasives between the cooperating parts (scraper-sliding metal sheet), the wear processes are significantly different compared to the case of coal alone, and to some extent they are similar to the wear in the presence of mineral abrasive (quartz sand), however, they show characteristic features specific to this type of abrasives. First of all, there are intensive cutting processes by the hard mineral grains. The grains are crushed during wear, however, such fragmented particles still cut the steel surfaces and generate wear debris-detached steel particles. The coal particles may be partially consolidated, but the interaction of the mineral grains breaks the coal layer. Defragmented coal coating layer facilitates the deposition of partially crushed hard abrasive grains at 
the points of cutting or penetration into the steel surface. Thus, the form of abrasive wear partially changes (loose grains of mineral abrasive still may affect the surface) from "three body" to "two body" form [31]. The latter form has a lower wear intensity compared to the first form.

The cyclical interaction of the scraper through the crushed particles of the coal layer and mineral grains causes the levelling the embedded rock grains to the steel surface and further crushing of the mineral abrasive and wear debris, which may partially mix with the coal fraction. The share of hard mineral fractions determines the wear intensity in a linear correlation.

Like the previous wear model, the concept of wear in the presence of a coal-mineral mixture (Figure 18) is divided into four stages:

- Stage I: fine grain fractions of transported coal mixed with mineral grains (e.g., sandstone) move to the metal sheet surface before contact with the scraper,

- $\quad$ Stage II: crushing the mineral grains and partial consolidation of the coal fraction under the load and the scraper advance, as well as cutting the surface by mineral grains,

- Stage III: continuation of cutting the steel surface by comminuted minerals, their deposition in the coal-filled areas of removed steel fragments from the surface layer and defragmentation of the pre-compacted coal fractions,

- Stage IV: smoothing the embedded or fixed mineral grains and partial inactivation of smaller particles by fragments of consolidated coal fractions.

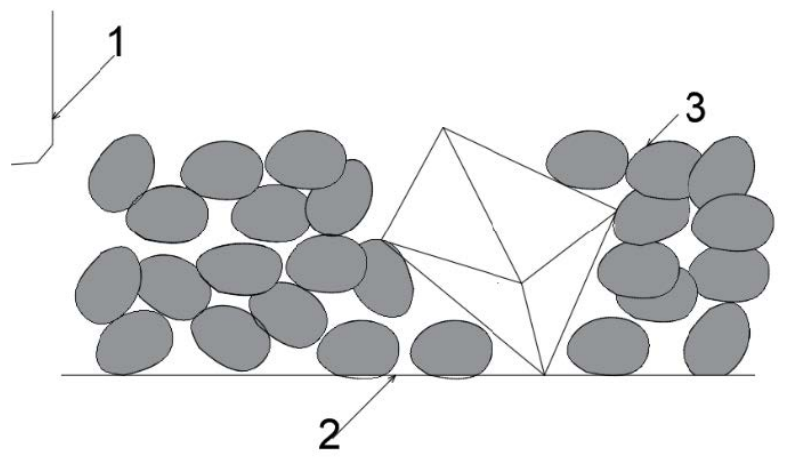

(a)

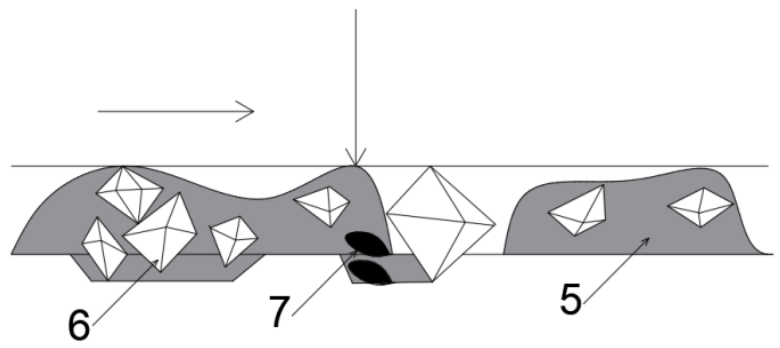

(c)

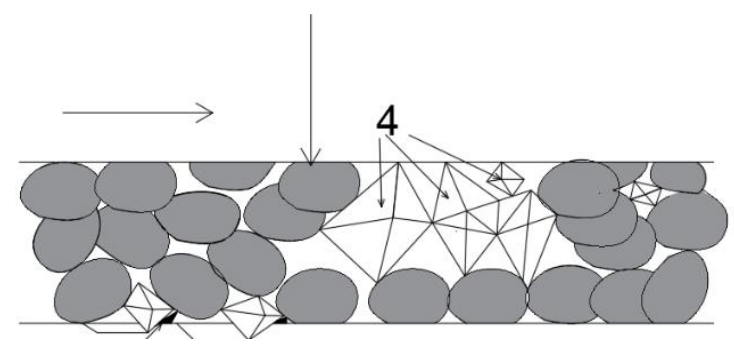

(b)

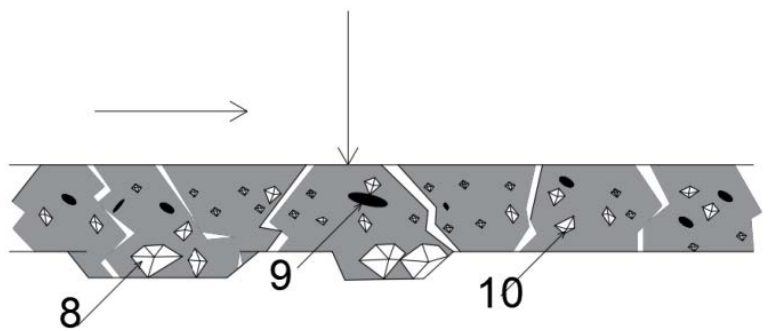

(d)

Figure 18. Model of wear with the presence of a coal-mineral mixture of a real system: a scraper sliding on the metal sheet surface, (a) - Stage I (initial state), (b)—Stage II (initial cutting of the steel surface by crushed and uncrushed mineral grains and initial coal consolidation under load and the scraper advance), (c)—Stage III (deposition of abrasive grains in coal-filled cutting areas or cracks), (d)—Stage IV (smoothing the mineral grains protruding above the surface level); symbols: 1-scraper, 2-metal sheet, 3-coal grains, 4-crushed mineral particles, 5-pre-consolidated coal fractions, 6-grains of hard abrasive embedded in the surface cavities, 7-wear debris, 8-smoothened mineral grains, 9-crushed particle of removed steel, 10—fully crushed mineral grains.

Referring to the work of Xia et al. [20], who specified the main types of wear such as abrasive wear, fatigue chipping and corrosion, corrosive wear of steel components in 
contact with various types of abrasives or without them should be still described. In the wear tests, corrosion products were found only in the case of wear without an abrasive between the cooperating surfaces. As already mentioned, this was the result of oxidation of the newly exposed surfaces. No corrosion was observed for other variants of the wear test, but it does not mean that this destructive process cannot take place. In the case of coal and coal-mineral abrasives, steel fragments were detached from the original surface by fatigue chipping or cutting. Such surfaces are also susceptible to corrosion, but simultaneously with the process of detaching the surface fragments, the resulting voids are likely to be filled with consolidated coal abrasive, which may limit oxygen access to the place of a possible oxidation. In the case of the wear only with the presence of hard mineral abrasive, the surface is exposed and oxidized immediately after cutting, however, the corrosion products were removed by the abrasive grains.

The presented models of wear of steel sample and description of the cooperating surfaces corrosion, showed that the impact of coal in the friction nodes of sliding components can on one hand, limit the possible wear effects, and on the other hand, intensifies certain destructive processes. The list of factors limiting and intensifying the wear with presence of coal and a coal-mineral mixture is presented in Table 7.

Table 7. List of factors limiting and intensifying the wear in the case of presence of coal and a coal-mineral mixture.

\begin{tabular}{|c|c|}
\hline \multicolumn{2}{|c|}{ Coal Abrasive } \\
\hline Factors Limiting the Wear & Factors Intensifying the Wear \\
\hline $\begin{array}{l}\text { The ability to form coal layers that cover surface irregularities, which } \\
\text { can separate steel surfaces from the crushed grains of mineral matter } \\
\text { contained in the coal abrasive. }\end{array}$ & $\begin{array}{l}\text { Transfer of load through the consolidated coal fractions to cooperating } \\
\text { surfaces and formation of fatigue chipping. }\end{array}$ \\
\hline $\begin{array}{l}\text { Capture of fragmented surface chipping particles and mineral grains by } \\
\text { consolidated coal fractions forming layers on the surface of worn steel. }\end{array}$ & $\begin{array}{l}\text { Possibility of accumulation of wear debris in the areas of surface cracks } \\
\text { and intensification of fatigue chipping (including in the areas of contact } \\
\text { of wear cuts and those related to the manufacture of steel surfaces). }\end{array}$ \\
\hline $\begin{array}{l}\text { Limiting the access of oxygen to the detached parts of the steel surface } \\
\text { by consolidated coal fractions. }\end{array}$ & $\begin{array}{l}\text { Cutting by the fragments of wear debris and partially by fine grains of } \\
\text { the mineral substance contained in the coal abrasive. }\end{array}$ \\
\hline $\begin{array}{l}\text { Limiting the possibility of contact of surface unevenness of cooperating } \\
\text { surfaces by the presence of coal fractions between them. }\end{array}$ & \\
\hline \multicolumn{2}{|c|}{ Coal-Mineral Abrasive } \\
\hline Factors Limiting Wear & Factors Intensifying Wear \\
\hline $\begin{array}{l}\text { Facilitating the placement of mineral abrasive grains in the areas of } \\
\text { surface damage and partial change of the form from "three-body } \\
\text { abrasive wear" to "two-body abrasive wear". }\end{array}$ & Cutting the surfaces by hard mineral grains and wear debris. \\
\hline $\begin{array}{l}\text { Limited capture of hard abrasive particles by defragmented } \\
\text { consolidated coal fraction. }\end{array}$ & $\begin{array}{l}\text { Possible formation of extensive surface cracks between cut areas as a } \\
\text { result of debris accumulation in the surface cracks. }\end{array}$ \\
\hline $\begin{array}{l}\text { Limitation of oxygen access to detached fragments of the steel surface } \\
\text { by consolidated coal fractions. }\end{array}$ & \\
\hline
\end{tabular}

\section{Conclusions}

Based on the tests, the following conclusions are drawn:

(1) The form of damage to the cooperating surfaces depends on the type of abrasive introduced between them:

- for coal abrasive, damage caused by fatigue chipping and cutting by wear products was found,

- for coal-mineral and mineral abrasives, surface damage caused by cutting with grains of the mineral fraction and flat chipping between the cuts were found,

- in the case of a lack of abrasive between the cooperating surfaces, traces of cutting by the unevenness of the cooperating surfaces and chipping surface fragments were found, and the presence of corrosion products in deeper cuts was noticed.

(2) In the case of coal-mineral abrasives, the deposition of hard grains in the damaged areas of the surface favoured by the presence of coal fractions was observed.

(3) For the coal abrasive, a residue from the grinding process was noticed after the wear tests. 
(4) On the basis of the measured volumes of wear debris the following was found:

- the highest wear was observed for the hard mineral abrasive (quartz sand),

- the lowest wear was observed for the coal abrasive and it was 10 times lower comparing to the wear for the mineral abrasive variant.

- wear degree for both wear-resistant steels was very similar,

- linear reduction in wear for the tested steels with reduction in share of hard grains was observed,

- wear with presence of coal abrasive was lower than wear without abrasives.

(5) In addition, the paper presents two models of wear in the presence of coal and coalmineral abrasives of the real tribological system-a scraper sliding on the surface of a metal sheet, as well as the possible impact of the presence of hard coal-based abrasives on the intensity of the wear process of the machines components, transporting energy resources, was determined.

(6) On the basis of the conducted tests, no significant influence of the chemical composition on the wear was found, the wear for both tested steels was very similar.

(7) As practice shows, by selecting steel for the slide plates of the chutes of scraper conveyors, attention is paid to the surface hardness, however, the resistance of the steel to fatigue surface chipping is also an important property.

The next stage of the research will be to determine the impact of selected hard coal parameters on wear tests (content of $C$ element, composition and type of mineral substance, grain size).

Author Contributions: Conceptualization, A.N.W.; methodology, A.N.W.; experimental studies A.N.W. and P.B.; formal analysis, I.J., K.S. and M.S.; investigation, I.J., A.N.W. and M.S.; resources, K.S. and P.B.; data curation, I.J., A.N.W. and M.S.; Writing-Original draft preparation, A.N.W.; Writing-Review and Editing, I.J., A.N.W., M.S., K.S. and P.B.; visualization, A.N.W. and I.J.; funding acquisition, A.N.W. and K.S. All authors have read and agreed to the published version of the manuscript.

Funding: The publication was made as part of BK-296/RG-2/2020, 06/020/BK_20/0046: Testing the resistance of the materials used in the components of roadway flight-bar conveyor to wear during action of rock abrasive materials.

Institutional Review Board Statement: Not applicable.

Informed Consent Statement: Not applicable.

Data Availability Statement: Not applicable.

Conflicts of Interest: The authors declare no conflict of interest.

\section{References}

1. Hawk, J.A.; Wilson, R.D. Tribology of Earthmoving, Mining, and Minerals Processing. In Modern Tribology Handbook; Bhushan, B., Ed.; CRC Press LLC: Boca Raton, FL, USA, 2001; Volume 35.

2. Lipson, C.; Vern Colwell, L. Handbook of Mechanical Wear: Wear, Frettage, Pitting, Cavitation, Corrosion; Literary Licensing, LLC: Whitefish, MT, USA, 2012.

3. Watterson, J.M. Tribology: A Simple Guide to the Study of Friction; Momentum Press: New York, NY, USA, 2019.

4. Tylczak, J.H. Abrasive wear. In ASM Handbook—Friction, Lubrication, and Wear Technology; ASM International: Almere, The Netherlands, 1992; Volume 18, pp. 184-190.

5. Myszka, D.; Wieczorek, A.N. An assessment of the applicability of austempered ductile iron containing Mo and Ni for mining machines parts. Arch. Metall. Mater. 2013, 58, 967-970. [CrossRef]

6. Wieczorek, A.N. Operation-oriented studies on wear properties of surface-hardened alloy cast steels used in mining in the conditions of the combined action of dynamic forces and an abrasive material. Arch. Metall. Mater. 2017, 62, 2381-2389. [CrossRef]

7. Wang, S.; Ge, Q.; Wang, J. The impact wear-resistance enhancement mechanism of medium manganese steel and its applications in mining machines. Wear 2017, 376, 1097-1104.

8. Wells, J.J.; Wigley, F.; Foster, D.J.; Gibb, W.H.; Williamson, J. The relationship between excluded mineral matter and the abrasion index of a coal. Fuel 2004, 83, 359-364. [CrossRef]

9. Wells, J.J.; Wigley, F.; Foster, D.J.; Livingston, W.R.; Gibb, W.H.; Williamson, J. The nature of mineral matter in a coal and the effects on erosive and abrasive behaviour. Fuel Process. Technol. 2005, 86, 535-550. [CrossRef] 
10. Gảhlin, R.; Jacobson, S. The particle size effect in abrasion studied by controlled abrasive surfaces. Wear 1999, $224,118-125$. [CrossRef]

11. Labaš, M.; Krepelka, F.; Ivaničová, L. Assessment of abrasiveness for research of rock cutting. Acta Montan. Slovaca 2012, 17, 65-73.

12. Suchánek, J.; Brožek, M. Abrasive wear resistance of selected hardfacing materials. In Proceedings of the Conference: NORDTRIB, Tromso, Norway, 1-3 June 2004; Volume 1. Available online: https:/ / www.researchgate.net/publication/307863719_ABRASIVE_ WEAR_RESISTANCE_OF_SELECTED_HARDFACING_MATERIALS (accessed on 28 February 2021).

13. Myszka, D.; Wieczorek, A.N. Effect of phenomena accompanying wear in dry corundum abrasive on the properties and microstructure of austempered ductile iron with different chemical composition. Arch. Metall. Mater. 2015, 60, 483-490. [CrossRef]

14. Wieczorek, A.N. Experimental studies on the influence of abrasive materials on the wear of hard-wearing steels. Tribologia 2018, 49, 133-141. [CrossRef]

15. Zum Gahr, K.-H. Microstructure and Wear of Materials; Elsevier: Amsterdam, The Netherlands, 1987 ; Volume 10.

16. Ratia, V.; Heino, V.; Valtonen, K.; Vippola, M.; Kemppainen, A.; Siitonen, P.; Kuokkala, V.-T. Effect of abrasive properties on the high-stress three-body abrasion of steels and hard metals. Tribologia 2014, 32, 3-18.

17. Hashemi, S.M. Minerals of coal main seam in Parvade coalfield (Tabas-Iran). In Proceedings of the 1st International Applied Geological Congress, Mashad Branch, Iran, 26-28 April 2010; Department of Geology, Islamic Azad University: Tehran, Iran, 2010; pp. 141-146.

18. Ngoy, E.K.; Mulaba-Bafunbiandi, A.F. An analytical model of coal abrasiveness index in function of the mineral composition of coal. In Proceedings of the International Conference on Chemical and Environmental Engineering, Johannesburg, South Africa, 15-16 April 2013; pp. 79-83.

19. Petrica, M.; Peissl, S.; Badisch, E. Influence of coal on the wear behavior of steels in 3-body conditions. Key Eng. Mater. 2014, 604, 75-78. [CrossRef]

20. Xia, R.; Li, B.; Wang, X.; Yang, Z.; Liu, L. Screening the Main Factors Affecting the Wear of the Scraper Conveyor Chute Using the Plackett-Burman Method. Math. Probl. Eng. 2019, 2019, 1204091. [CrossRef]

21. Tlotleng, M.T. Coal Characteristics that Lead to Abrasion during Grinding. Master's Thesis, University of the Witwatersrand, Johannesburg, South Africa, 2011.

22. Jonczy, I.; Wieczorek, A.N.; Podwórny, J.; Gerle, A.; Staszuk, M.; Szweblik, J. Characteristics of hard coal and its mixtures with water subjected to friction. Gospod. Surowcami Miner. (Miner. Resour. Manag.) 2020, 36, 185-201.

23. Wieczorek, A.N. Designing machinery and equipment in accordance with the principle of sustainable development. Manag. Syst. Prod. Eng. 2015, 17, 28-34.

24. Ojala, N.; Valtonen, K.; Heino, V.; Kallio, M.; Aaltonen, J.; Siitonen, P.; Kuokkala, V.T. Effects of composition and microstructure on the abrasive wear performance of quenched wear resistant steels. Wear 2014, 317, 225-232. [CrossRef]

25. Berkowitz, N. An Introduction to Coal Technology, 2nd ed; Academic Press: Cambridge, MA, USA, 1994.

26. Berkowitz, N. The Chemistry of Coal; Elsevier: Amsterdam, The Netherlands, 1995; Volume 7.

27. Terva, J.; Teeri, T.; Kuokkala, V.T.; Siitonen, P.; Liimatainen, J. Abrasive wear of steel against gravel with different rock-steel combinations. Wear 2009, 267, 1821-1831. [CrossRef]

28. Shao, H.S.; Chen, H.H. Study on abrasive wear characteristics of coal. J. China Coal Soc. 1983, 12, 97-100.

29. Salehi, M. Delaminationwearmechanism in gray cast irons. Int. J. Eng. 2000, 13, 37-50.

30. Stachowiak, A.; Zwierzycki, W. Delamination wear of steel AISI 304 in tribocorrosive conditions. Tribologia 2010, 5, 315-322.

31. Stachowiak, G.B.; Stachowiak, G.W. The effects of particle characteristics on three-body abrasive wear. Wear 2001, 249, 201-207. [CrossRef] 